Universidade de São Paulo

Faculdade de Medicina de Ribeirão Preto

\title{
2018
}

EFEITO DA ESTIMULAÇÃO ELÉTRICA DE ALTA

VOLTAGEM NA INTEGRAÇÃO DE ENXERTOS DE PELE TOTAL EM RATOS SUBMETIDOS À AÇÃO DA NICOTINA
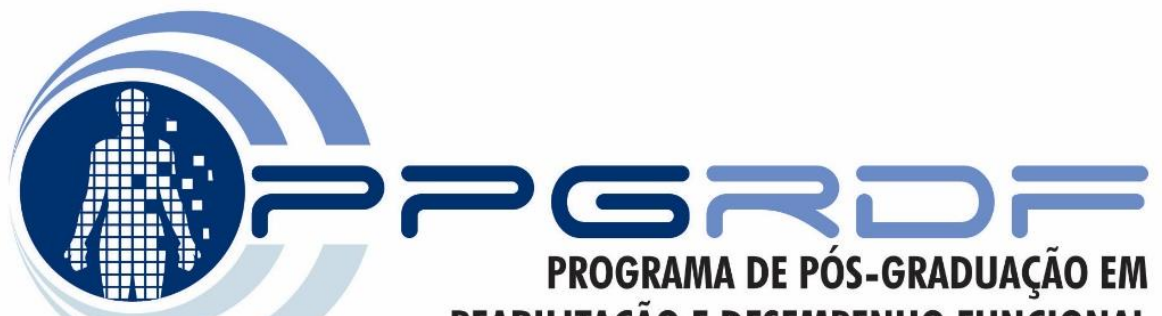

PROGRAMA DE PÓS-GRADUAÇÃO EM REABILITAÇÃO E DESEMPENHO FUNCIONAL

FMRP-USP

Ana Karina de Souza

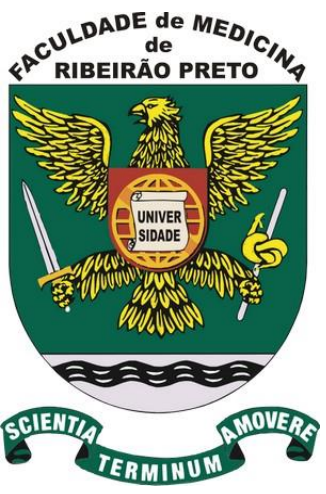

Dissertação 


\title{
UNIVERSIDADE DE SÃO PAULO
}

FACULDADE DE MEDICINA DE RIBEIRÃO PRETO

\author{
ANA KARINA DE SOUZA
}

EFEITO DA ESTIMULAÇÃO ELÉTRICA DE ALTA VOLTAGEM NA INTEGRAÇÃO DE ENXERTOS DE PELE TOTAL EM RATOS SUBMETIDOS À AÇÃO DA NICOTINA

Versão corrigida. A versão original encontra-se disponível tanto na Biblioteca da Unidade que aloja o Programa, quanto na Biblioteca Digital de Teses e Dissertações da USP (BDTD).

Ribeirão Preto 


\section{EFEITO DA ESTIMULAÇÃO ELÉTRICA DE ALTA VOLTAGEM NA INTEGRAÇÃO DE ENXERTOS DE PELE TOTAL EM RATOS SUBMETIDOS À AÇÃO DA NICOTINA}

Dissertação apresentada ao Programa de PósGraduação em Reabilitação e Desempenho Funcional - FMRP/USP, pelo Departamento de Biomecânica, Medicina e Reabilitação do Aparelho Locomotor para obtenção do Título de Mestre em Ciências.

Área de concentração: Fisioterapia

Orientadora: Profa. Dra. Elaine C. O. Guirro

\section{Ribeirão Preto}




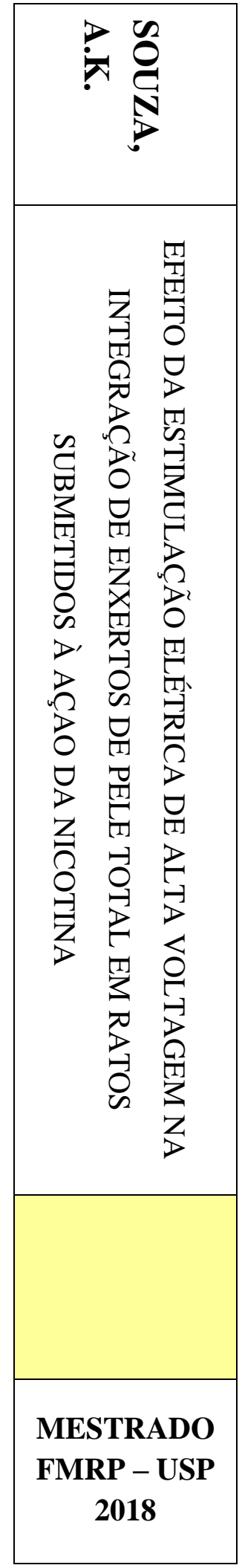


AUTORIZO A REPRODUÇÃO E DIVULGAÇÃO TOTAL OU PARCIAL DESTE TRABALHO, POR QUALQUER MEIO CONVENCIONAL OU ELETRÔNICO, PARA FINS DE ESTUDO E PESQUISA, DESDE QUE CITADA A FONTE.

Catalogação da Publicação

Serviço de Documentação da Faculdade de Medicina

Faculdade de Medicina de Ribeirão Preto da Universidade de São Paulo

De Souza, Ana Karina

Efeito da estimulação elétrica de alta voltagem na integração de enxertos de pele total em ratos submetidos à ação da nicotina. Ribeirão Preto 2018.

84p.: il, $30 \mathrm{~cm}$.

Orientadora: Guirro, Elaine Caldeira de Oliveira.

Dissertação (Mestrado) - Programa de Pós-Graduação em

Reabilitação e Desempenho Funcional. Universidade de São Paulo,

Faculdade de Medicina de Ribeirão Preto - USP.

1. Enxertia de pele, 2.Estimulação elétrica, 3.Cicatrização, 4.Nicotina, 5.Fisioterapia. 
Nome: Ana Karina de Souza

Título: Efeito da estimulação elétrica de alta voltagem na integração de enxertos de pele total em ratos submetidos à ação da nicotina

Dissertação apresentada ao Programa de Pós-Graduação em Reabilitação e Desempenho Funcional - FMRP/USP para obtenção do Título de Mestre em Ciências. Área de Concentração: Fisioterapia

Aprovado em:

\author{
Banca Examinadora
}

Prof. Dr. Instituição:

Julgamento: Assinatura:

Prof. Dr. Instituição:

Julgamento: Assinatura:

Prof. Dr. Instituição:

Julgamento: Assinatura: 
Dedicatória 
Dedico meu mestrado primeiramente a Deus, que sem Ele nada faria sentido algum, Ele que me deu o dom da vida! Obrigada, Pai, Amigo, Senhor! A Ti não preciso dizer nada, Sabes tudo. Dedico também à minha mãe, Maria Cepolini de Souza, à quem muito me espelho e sou eternamente grata por tê-la em minha vida. 
Agradecimentor 
Agradeço primeiramente à minha orientadora, Profa. Dra Elaine Caldeira de Oliveira Guirro, por me passar de forma tão sábia seus conhecimentos. Obrigada por todo auxílio, apoio e por ter confiado a mim esta tarefa na produção deste estudo.

A minha mãe Maria Cepolini de Souza que sempre me estimulou a buscar novos conhecimentos, e me ensinou o principal significado de respeito, responsabilidade e caráter. Aos meus queridos avós José Roberto de Souza e Carmen Silvia Straceri de Souza por sempre se dedicarem a mim com tanto zelo e carinho, obrigada por me auxiliarem sem poupar esforços na minha educação.

Ao meu pai, de quem sinto imensas saudades, más sei que onde quer que esteja, está sempre intercedendo por mim.

Ao meu namorado André Barreto Rodrigues, que, com muito amor e paciência não poupou esforços para sempre me ajudar, independentemente de qualquer situação. Muito obrigada pela partilha, companheirismo e por fazer parte e total diferença na minha vida. Você é muito amado.

A minha amiga e companheira Thamires Rodrigues de Souza, que esteve ao meu lado em todos os momentos, e que sem ela, este trabalho jamais poderia ter sido concluído. Obrigada por tudo, principalmente pela sua amizade incondicional! Vou te levar por toda vida! Agradeço imensamente também a Laís Mara Siqueira das Neves, a quem tenho muita admiração e carinho e que não poupou esforços para me ajudar e me ensinar tudo o que eu precisava para conduzir este estudo, sempre com muita paciência e dedicação. Obrigada! Agradeço também a minha amiga Gabriella de Paula Ferreira Leite por todo auxílio durante o estudo, principalmente no biotério, mesmo à distância. Obrigada!

Agradeço ao meu irmão José Roberto de Souza Neto e minha cunhada Karina Gazola Crevelari por serem sempre presentes em diversas etapas de minha vida.

Ao meu sogro José Rogério Rodrigues, a quem tenho como pai, que sempre me fortaleceu para prosseguir e batalhar pelos meus sonhos. Agradeço também à minha sogra Márcia Barreto Rodrigues, por se fazer presente, mesmo longe. Seus conselhos sempre foram de extrema importância para mim. 
Agradeço aos companheiros de laboratório (Vânia, Carla, Monique, Adriana Gonçalves, Adriana Mendonça, Daniela, Camila, Paola, Roberta, Thaís e Emilson) por fazerem o LAIDEF ter se tornado a minha segunda família. Agradeço também ao professor Dr. Rinaldo Roberto de Jesus Guirro, por todo o conhecimento transmitido e aos pesquisadores do LARF.

Às técnicas Rosangela e Érika por toda paciência e por me ajudar confeccionando as lâminas, ao técnico Tenysson por me ensinar no manuseio de programas e equipamentos, e também ao Rubens Salomão por cuidar do biotério.

Ao professor Dr. Sérgio Brito Garcia, grande colaborador. Agradeço por toda parceria na realização e análise imunohistoquímica. Sem sua ajuda, este trabalho não teria tanta qualidade.

Aos funcionários da Universidade de São Paulo, especialmente ao Samuel Filipini por me orientar com a parte burocrática do mestrado.

A equipe do REMA (Reabilitação de mastectomizadas) por me receberem tão bem e por todo conhecimento transmitido. Agradeço também a todas as pacientes que tive o prazer em atender e conhecer. Vocês me possibilitaram um grande aprendizado profissional e pessoal, e me fizeram crescer muito! Obrigada! 
“Tu, ó Senhor Deus, és tudo o que tenho. O meu futuro está em Tuas mãos. Tu diriges a minha vida."

(Salmos 16:5) 


\section{RESUMO}

SOUZA, AK. Efeito da estimulação elétrica de alta voltagem na integração de enxertos de pele total em ratos submetidos à ação da nicotina [Dissertação]. Ribeirão Preto: Universidade de São Paulo, Faculdade de Medicina de Ribeirão Preto, 2018. 84f.

O procedimento cirúrgico de transplante de pele ou enxertia tem grande utilização em cirurgia plástica reparadora, e a influência de recursos terapêuticos na viabilidade deste, sob a ação da nicotina, ainda não está fundamentada. O objetivo do estudo foi avaliar a influência da estimulação elétrica de alta voltagem (EEAV) na integração de enxerto de pele total em ratos submetidos à ação da nicotina. Para tanto, foram analisados 60 ratos machos, adultos, da linhagem Wistar distribuídos aleatoriamente em 6 grupos de 10 animais: Grupo 1 (Sham) - animais submetidos ao procedimento cirúrgico de enxertia de pele; Grupo 2 - animais submetidos ao procedimento cirúrgico de enxertia de pele, e posteriormente, submetidos a EEAV anódica; Grupo 3 - animais submetidos ao procedimento cirúrgico de enxertia de pele, e posteriormente, submetidos a EEAV catódica; Grupo 4 - animais submetidos à ação da nicotina e, posteriormente submetidos ao procedimento cirúrgico de enxertia de pele Grupo 5- animais submetidos à ação da nicotina, posteriormente submetidos ao procedimento cirúrgico de enxertia de pele e em seguida submetidos à EEAV anódica; Grupo 6- animais submetidos à ação da nicotina e, posteriormente submetidos ao procedimento cirúrgico de enxertia de pele e em seguida submetidos à EEAV catódica. A aplicação da EEAV foi efetuada por sete dias (frequência de $10 \mathrm{~Hz}$; limiar motor, 20 $\mu \mathrm{s}$, e $100 \mu \mathrm{s}$ ), com início no terceiro dia após a cirurgia e após a retirada do curativo do enxerto. Foi analisada a porcentagem de contração tecidual do enxerto (software Image $\mathbf{J}^{\circledR}$ ), circulação do enxerto, por meio de imagem infravermelha (FLIR ${ }^{\circledR}$ T300s). Também foi avaliada a espessura da epiderme, infiltrados inflamatórios e área de gap (Hematoxilina-eosina), imunohistoquímica para fator de crescimento do endotélio vascular (VEGF - Vascular Endotelial Growth Factor), e Fator VIII para contagem de número de vasos sanguíneos. Para a análise estatística foi aplicado o teste ANOVA seguido de Dunkan. O processamento dos dados foi efetuado pelo software SAS (Cary, $\mathrm{NC})$, versão 9.3, sendo fixado o nível crítico de $5 \%(\mathrm{p}<0,05)$. A estimulação elétrica de alta voltagem anódica promoveu maior integração do enxerto demonstrando menor porcentagem de contração tecidual, menor quantidade de infiltrados inflamatórios e maior quantidade de fator de crescimento do endotélio vascular, além de maior número de vasos sanguíneos neoformados Diante dos achados, pode-se concluir que a estimulação elétrica de alta voltagem pode influenciar positivamente na integração do enxerto de pele em ratos submetidos à nicotina.

Palavras-chave: Enxertia de pele, Estimulação elétrica, Cicatrização, Nicotina, Fisioterapia. 


\begin{abstract}
SOUZA, AK. Effect of high voltage electrical stimulation on the integration of total skin grafts in rats submitted to nicotine action [Dissertation]. Ribeirão Preto: University of São Paulo, Faculty of Medicine of Ribeirão Preto, 2018. 84f.

The surgical procedure of skin grafting or grafting has great use in restorative plastic surgery, and the influence of therapeutic resources on the viability of this, under the action of nicotine, is not yet substantiated. The aim of the study was to evaluate the influence of high voltage electrical stimulation (EEAV) on the integration of total skin graft in rats submitted to nicotine action. For this purpose, 60 adult Wistar male rats randomly distributed in 6 groups of 10 animals were analyzed: Group 1 (Sham) animals submitted to the surgical procedure of skin grafting; Group 2 - animals submitted to the surgical procedure of grafting of the skin, and later, submitted to anodic EEAV; Group 3 - animals submitted to the surgical procedure of skin grafting, and subsequently, submitted to cathodic EEAV; Group 4 - animals submitted to the action of nicotine and subsequently submitted to the surgical procedure of grafting of skin Group 5 animals submitted to the action of nicotine, later submitted to the surgical procedure of grafting of the skin and then submitted to anodic HVAC; Group 6 animals submitted to the action of nicotine and subsequently submitted to the surgical procedure of skin grafting and then submitted to cathodic HVAC. The application of EEAV was performed for seven days (frequency of $10 \mathrm{~Hz}$, motor threshold, $20 \mu \mathrm{s}$, and $100 \mu \mathrm{s}$ ), starting on the third day after surgery and after removal of the dressing from the graft. The percentage of graft tissue contraction (Image J® software), graft circulation, was analyzed by means of infrared image (FLIR ${ }^{\circledR}$ T300s). The thickness of the epidermis, inflammatory infiltrates and gap area (Hematoxylin-eosin), immunohistochemistry for vascular endothelial growth factor (VEGF), and factor VIII for blood vessel count were also evaluated. For the statistical analysis the ANOVA test followed by Dunkan was applied. Data processing was performed by the SAS software (Cary, NC), version 9.3, and the critical level was set at 5\% ( $\mathrm{p}<0.05)$. Anodic high voltage electrical stimulation promoted greater graft integration, demonstrating a lower percentage of tissue contraction, a lower amount of inflammatory infiltrates and a greater amount of vascular endothelial growth factor, as well as a greater number of newly formed blood vessels. In view of the findings, it was concluded that high voltage electrical stimulation can positively influence the integration of the skin graft in rats submitted to nicotine.
\end{abstract}

Keywords: Skin stimulation, Electrical stimulation, Healing, Nicotine, Physiotherapy. 


\section{LISTA DE FIGURAS}

Figura 1 - Fluxograma demonstrando o delineamento do estudo.

Figura 2 -Imagem ilustrativa demonstrando o procedimento cirúrgico: A - Demarcação do Enxerto com as medidas padrão 2X2; B - Ressecção dos segmentos cutâneos e a colocação destes em soro fisiológico; C e D- Aplicação dos enxertos nas áreas receptoras transpondo as peles das respectivas áreas; D: Pontos simples nos 4 vértices e entre eles ponto simples com sobra de linha; E: Aplicação de gaze e curativo Rayon F: amarração dos fios - Brown ou tipo tie over. (Fonte: arquivo pessoal). 31

Figura 3 - Imagem mostrando a aplicação do equipamento de estimulação elétrica de alta voltagem. (Fonte: arquivo pessoal). 32

Figura 4 - Imagem ilustrativa do dispositivo confeccionado para padronização da pressão do eletrodo no enxerto. (Fonte: arquivo pessoal)

Figura 5 - Imagem ilustrativa do software Image $\mathrm{J}{ }^{\circledR}$ apontando a demarcação do perímetro do enxerto e o valor da área correspondente em pixels. (Fonte: arquivo pessoal)

Figura 6 - Imagem do equipamento utilizado para padronizar a distância das imagens termográficas. (Fonte: arquivo pessoal).

Figura 7 -Imagem demonstrando os marcadores de isopor nos quatro vértices do enxerto para facilitar a compreensão da imagem no software. (Fonte: arquivo pessoal).....

Figura 8 - Imagem do software Research IR FLIR ${ }^{\circledR}$ mostrando a demarcação de todo o perímetro do enxerto.(Fonte: arquivo pessoal). .36

Figura 9 - Imagem microscópica histológica ilustrativa da medida da espessura da epiderme em $\mu \mathrm{m}$ dos enxertos com a coloração Hematoxilina e Eosina (HE). (Fonte: arquivo pessoal).

Figura 10 - Imagem microscópica histológica ilustrativa da medida dos infiltrados inflamatórios em $\mu \mathrm{m}$ dos enxertos com a coloração Hematoxilina e Eosina (HE). (Fonte: arquivo pessoal).

Figura 11 - Imagem microscópica histológica ilustrativa da medida da área de gap do enxerto com a coloração Hematoxilina e Eosina (HE). (Fonte: arquivo pessoal).............38

Figura 12- Fotomicrografias da imunomarcação de anticorpo primário para AntiVEGFA. Representação dos grupos: A - Grupo 1; B - Grupo 2; C - Grupo 3; D Grupo 4; E-Grupo 5; F- Grupo 6. (Fonte: arquivo pessoal).

Figura 13 - Fotomicrografias da imunomarcação de anticorpo primário para Anti-fator VIII. Representação dos grupos: A - Grupo 1; B - Grupo 2; C - Grupo 3; D - Grupo 4; E - Grupo 5; F- Grupo 6. (Fonte: arquivo pessoal). 
Figura 14 - Gráfico em Box-plot da porcentagem de contração do enxerto cutâneo.....45

Figura 15 - Comportamento da temperatura ao longo do tempo para os diferentes grupos de acordo com os dias avaliados. Grupo 1 - Sham; Grupo 2- EEAV+; Grupo 3 EEAV; Grupo 4- Nicotina; Grupo 5 - Nicotina e EEAV +; Grupo 6 - Nicotina e EEAV -. (Fonte: arquivo pessoal)

Figura 16 - Gráfico em Box-plot da temperatura do terceiro (Dia 3) e décimo dia (Dia 10). Grupo 1 - Sham; Grupo 2- EEAV+; Grupo 3 - EEAV-; Grupo 4- Nicotina; Grupo 5 -Nicotina e EEAV +; Grupo 6 - Nicotina e EEAV-. (Fonte: Arquivo pessoal) .49

Figura 17 - Gráfico em Box-plot da espessura da epiderme. .51

Figura 18 - Gráfico em Box-plot da espessura espessura dos infiltrados inflamatórios.53

Figura 19 - Gráfico em Box-plot da área de gap. .55

Figura 20 - Gráfico em Box-plot do fator de crescimento do endotélio vascular (VEGF) .57

Figura 21 - Gráfico em Box-plot do Fator VIII .59 


\section{LISTA DE TABELAS}

Tabela 1 - Valores das porcentagens média e desvios-padrão de contração do enxerto nos grupos estudados (\%).

Tabela 2 - Valores das temperaturas médias e desvios-padrão dos enxertos nos grupos estudados $\left({ }^{\circ} \mathrm{C}\right)$ de acordo com os dias avaliados. 46

Tabela 3 - Valores médios da espessura da epiderme e desvios-padrão do enxerto nos grupos estudados $(\mu \mathrm{m})$

Tabela 4 - Valores médios da espessura dos infiltrados inflamatórios e desvios-padrão do enxerto nos grupos estudados $(\mu \mathrm{m})$.

Tabela 5 - Valores médios da área de gap e desvios-padrão do enxerto nos grupos estudados $(\mu \mathrm{m})$ 54

Tabela 6 - Valores médios e desvios-padrão da quantidade de fator de crescimento do endotélio vascular (VEGF) dos enxertos, nos grupos estudados

Tabela 7 - Valores médios referentes ao fator VIIII e desvios-padrão do enxerto nos grupos estudados $(\mu \mathrm{m})$. 


\section{LISTA DE ABREVIAÇÕES}

\begin{tabular}{|c|c|}
\hline o & Grau \\
\hline${ }^{\circ} \mathrm{C}$ & Grau Celsius \\
\hline$\%$ & Por cento \\
\hline$\mu \mathrm{m}$ & Micrômetro \\
\hline ANOVA & Análise de Variância \\
\hline CETEA & Comissão de Ética em Experimentação Animal \\
\hline $\mathrm{Cm}$ & Centímetros \\
\hline $\mathrm{CN}$ & Carolina do Norte \\
\hline DP & Desvio Padrão \\
\hline FMRP & Faculdade de Medicina de Ribeirão Preto \\
\hline EEAV & Estimulação Elétrica de Alta Voltagem \\
\hline g & Grama \\
\hline $\mathrm{HE}$ & Hematoxilina e Eosina \\
\hline $\mathrm{Hz}$ & Hertz \\
\hline $\mathrm{mg} / \mathrm{dL}$ & Miligramas por decilitro \\
\hline $\mathrm{mg} / \mathrm{kg}$ & Miligrama por quilo \\
\hline $\mathrm{mL} / 100 \mathrm{~g}$ & Mililitros por cem gramas \\
\hline $\mathrm{nm}$ & Nanômetro \\
\hline $\mathrm{Mv}$ & Millivolts \\
\hline $\mathrm{PO}$ & Pós- operatório \\
\hline DP-trans & Potencial elétrico transepitelial \\
\hline TRAM & $\begin{array}{l}\text { Retalho miocutâneo transverso do reto- } \\
\text { abdominal. }\end{array}$ \\
\hline USA & United States of America \\
\hline VEGF & Fator de crescimento endotelial vascular \\
\hline
\end{tabular}




\section{SUMÁRIO}

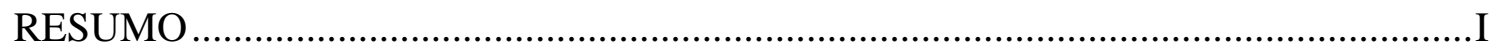

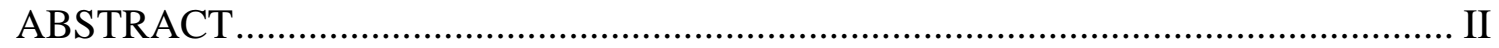

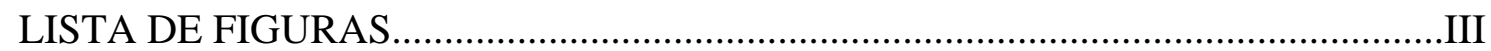

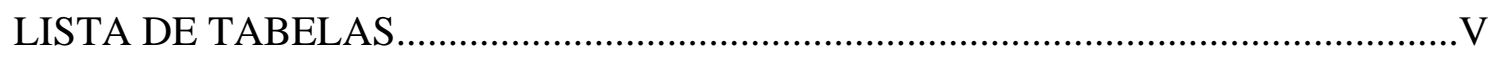

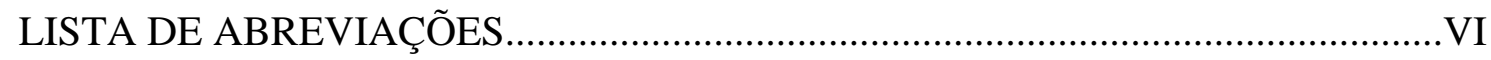

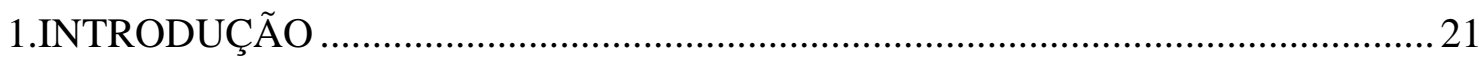

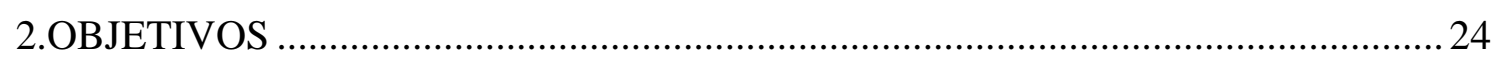

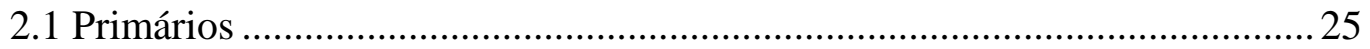

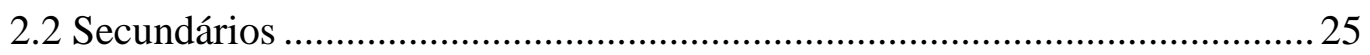

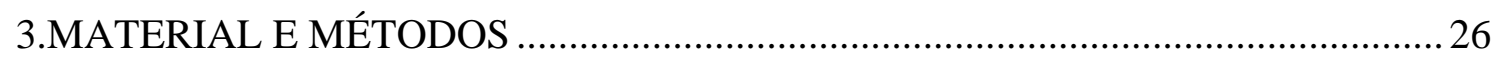

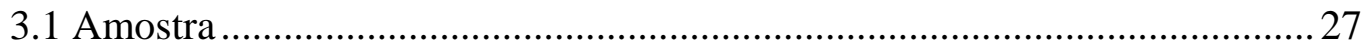

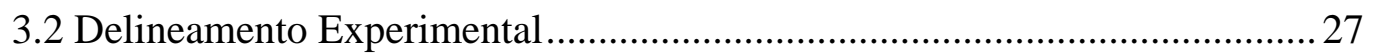

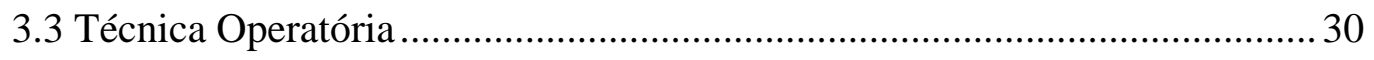

3.4 Procedimento Terapêutico com estimulação elétrica de alta voltagem .........31

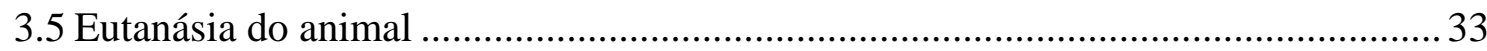

3.6 Análise de porcentagem de contração da área do Enxerto (Image $\mathbf{J}^{\circledR}$ ) ..................... 33

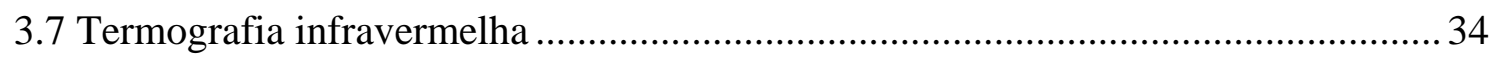

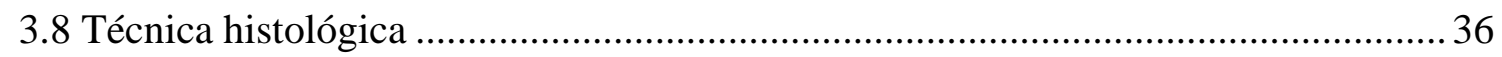

3.8.1 Morfometria para avaliação da espessura da epiderme, infiltrados

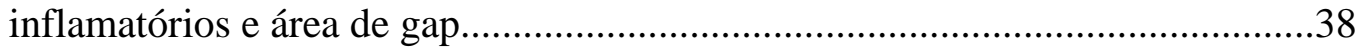

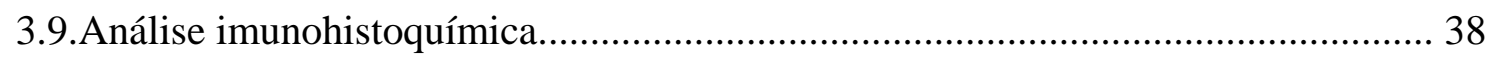

3.9.1 Morfometria para avaliação do VEGF e Fator VIII..................................39

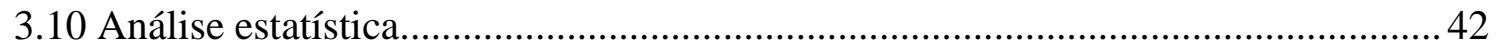

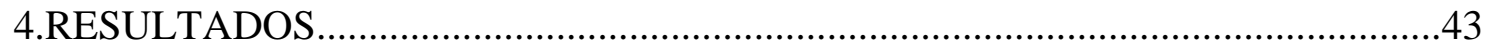

4.1 Valores percentuais da contração do enxerto............................................. 44

4.2 Valores referentes a temperatuira do enxerto...........................................45

4.3 Valores referentes a espessura da epiderme do enxerto..............................50

4.4 Valores referentes a espessura dos infiltrados inflamatórios do enxerto........52

4.5 Valores referentes a espessura do gap......................................................54 
4.6 valores referentes da quantidade de fator de crescimento do endotélio

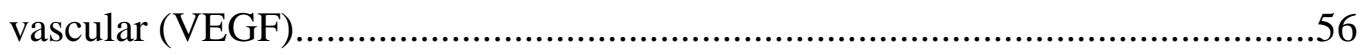

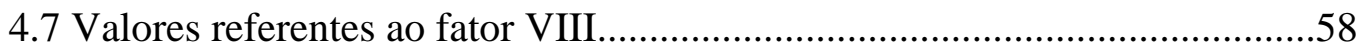

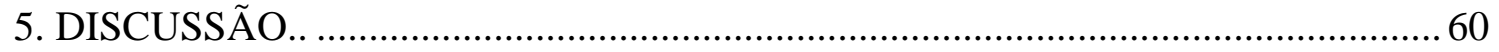

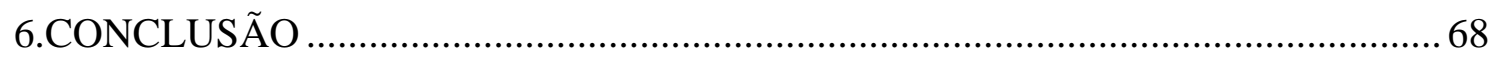

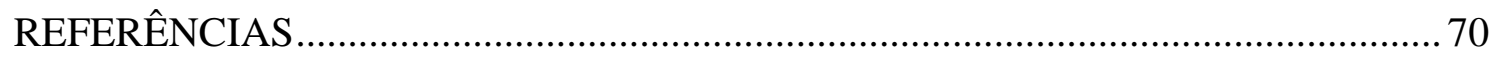

ANEXO 
Introdução 


\section{INTRODUÇÃO}

A enxertia de pele é um procedimento operatório importante na cirurgia plástica, considerado também uma arma valiosa no arsenal da cirurgia reconstrutiva. São indicados em casos de reconstrução por traumas ou feridas, extirpação de tumores, queimaduras e infecções (Young, Fowler, 1998; Francis, Baynosa, 2017).

A associação entre a cicatrização de feridas e o tabagismo tem sido investigada (Aköz, Akan, Yildirim, 2002). A cicatrização de feridas é um processo fisiopatológico complexo, e lesões crônicas não respondem bem a um tratamento isolado A enxertia é cada vez mais bem reconhecida como benéfica para lesões agudas ou crônicas, considerada eficiente até em pacientes refratários a outros tratamentos, entretanto, pode ser afetada pela nicotina (Siana e Rex, 1989; Witte, Barbul, 1997; Jorgensen et al., 1998; Ma et al., 2000; Maderal, Kirsner, 2016)..

A nicotina liberada do fumo acarreta um efeito vasoativo limitado na pele e tecido subcutâneo, o que claramente reduz o fluxo sanguíneo do tecido, comprometendo o metabolismo aeróbio, e é reconhecida como principal causadora de complicações pósoperatórias de feridas em indivíduos fumantes (Sørensen et al., 2009; Xanthoulea et al., 2013; Dinos et al., 2015; Pluvy et al., 2015), interferindo na síntese de colágeno, e prejudicando o processo de cicatrização (Jorgensen et al., 1998; Biondo-Simões et al., 2009).

Tanto o ato de fumar, quanto a aplicação de emplastros de nicotina na pele de pacientes, tem como consequência a inibição do fluxo de oxigênio para os tecidos em cicatrização (Medeiros, 2003).

Existem agentes eletrofísicos que podem influenciar positivamente no processo de cicatrização, como a utilização do laser de baixa intensidade (Fujino et al., 1986), terapia por pressão negativa (Landau et al., 2008; Nease, 2009) e ultrassom terapêutico (Amâncio et al., 2006; Gonçalves et al., 2007). A estimulação elétrica pode interferir na cicatrização de feridas, direcionando a migração celular durante o processo (Zhao et al., 2010), reduzindo a isquemia (Goldman et al., 2004), e incrementando a microcirculação; podendo vir a ser um complemento eficaz e seguro, e, como consequência, potencializar processos de reparação, além de aumentar a viabilidade de retalhos (Goldman, Brewley, Golden, 2002; Neves et al., 2016). 
A aplicação da estimulação elétrica de alta voltagem no tratamento de diferentes lesões cutâneas tem sido investigada (Silva et al., 2010; Franek et al., 2012; Castana et al., 2013; Kim, Cho, Lee, 2014; Polak, Franek, Taradaj, 2014; Ud-Din, Bayat, 2014), entretanto, a influência deste recurso em enxertias sob a influência da nicotina ainda não está estabelecida, e seu papel na cicatrização em pacientes fumantes é desconhecido.

Diante do grande número de indivíduos fumantes, justifica-se a importância de um estudo que avalie o efeito do recurso como alternativa para minimizar os efeitos deletérios da nicotina na integração do enxerto de pele total. 
Objetivos 


\section{OBJETIVOS}

\subsection{Primários}

Avaliar os efeitos da estimulação elétrica de alta voltagem na integração de enxertos de pele total em ratos submetidos à ação da nicotina.

\subsection{Secundários}

Analisar a porcentagem de contração dos enxertos;

Analisar a temperatura dos enxertos;

Analisar a espessura da epiderme dos enxertos;

> Analisar o tamanho do infiltrado inflamatório;

$>$ Analisar a área de gap (falta de integração);

$>$ Analisar o fator de crescimento do endotélio vascular por meio de imunohistoquímica;

Analisar o número de vasos sanguíneos por meio de imunohistoquímica. 
Materiale Métodos 


\section{MATERIAL E MÉTODOS}

\subsection{Amostra}

Foram avaliados 60 ratos machos, adultos, com cerca de três meses de idade, pesados entre 280 gramas a 310 gramas, da linhagem Wistar, fornecidos pelo Biotério Central da Faculdade de Medicina de Ribeirão Preto, Universidade de São Paulo (FMRP-USP). Os procedimentos experimentais foram realizados no laboratório do Programa de Pós-Graduação em Reabilitação e Desempenho Funcional. Os animais foram mantidos em biotério, com ciclo claro-escuro de 12 horas, alojados em gaiolas individuais, recebendo ração comercial e água ad libitum.

O projeto foi aprovado pela Comissão de Ética em Experimentação Animal (CETEA) da Faculdade de Medicina de Ribeirão Preto (FMRP/USP), sob protocolo número 147/2015 (Anexo 1).

\subsection{Delineamento Experimental}

Os enxertos foram delineados com dimensões de $2 \mathrm{~cm}$ de comprimento por $2 \mathrm{~cm}$ de largura (Amâncio et al., 2006), sendo realizado no dorso de cada animal. A disposição dos enxertos foi estabelecida entre as escápulas, abaixo do ângulo inferior da escápula, e $3 \mathrm{~cm}$ abaixo do prime00iro enxerto.

Os animais foram pesados e distribuídos aleatoriamente em 6 grupos de 10 animais:

* Grupo 1 (Sham) - animais submetidos ao procedimento cirúrgico de enxerto de pele, em seguida à aplicação simulada da corrente.

* Grupo $2(\mathrm{EEAV}+)$ - animais submetidos ao procedimento cirúrgico de enxerto de pele, e posteriormente submetidos à estimulação elétrica de alta voltagem anódica.

- Grupo 3 (EEAV-) - animais submetidos ao procedimento cirúrgico de enxerto de pele, e posteriormente submetidos à estimulação elétrica de alta voltagem catódica. 
* Grupo 4 (Nicotina) - animais submetidos à injeção de nicotina injetada na tela subcutânea em uma dose de $2 \mathrm{mg} / \mathrm{Kg}, 2 \mathrm{x}$ ao dia, por um período de 28 dias até o procedimento cirúrgico, e posteriormente, submetidos ao procedimento cirúrgico de enxerto de pele (Neves et al, 2011).

* Grupo 5 (Nicotina + EEAV+) - animais submetidos à injeção de nicotina injetada na tela subcutânea em uma dose de $2 \mathrm{mg} / \mathrm{Kg}, 2 \mathrm{x}$ ao dia, por um período de 28 dias até o procedimento cirúrgico, e posteriormente, submetidos ao enxerto de pele. Em seguida, foi aplicada a estimulação elétrica de alta voltagem anódica.

* Grupo 6 (Nicotina + EEAV-) - animais submetidos à injeção de nicotina injetada na tela subcutânea em uma dose de $2 \mathrm{mg} / \mathrm{Kg}$, 2x ao dia, por um período de 28 dias até o procedimento cirúrgico, e posteriormente submetidos a técnica de enxerto de pele. Em seguida, foi aplicada a estimulação elétrica de alta voltagem catódica.

A nicotina usada no experimento (Nicotina Sulfato L-1 Metil-2 (3-Piridil) Pirrolidina Sulfato; grau II; PM 422-6; SIGMA), foi diluída com solução salina para a concentração de 1mg/mL (Gomes et al., 2004), e injetada no tecido subcutâneo dos ratos por 28 dias até o ato cirúrgico.

O curativo do enxerto foi removido no terceiro dia pós-operatório e a partir deste dia foi aplicada a estimulação elétrica de alta voltagem. Foram realizadas sessões diárias de 30 minutos de duração cada e repetidas por sete dias consecutivos, sempre no mesmo horário, para respeitar o intervalo de 24 horas entre as sessões (Amâncio et al., 2006). O delineamento do estudo está descrito na Figura 1. 


\begin{tabular}{|c|c|c|c|c|c|c|c|}
\hline \multirow[b]{2}{*}{ Sham } & \multicolumn{2}{|c|}{ DUÇÃO DA NICOTINA } & \multicolumn{2}{|c|}{$\begin{array}{c}\text { DESCANSO } \\
2 \text { DIAS }\end{array}$} & \multirow{2}{*}{$\begin{array}{c}\text { EEAV } \\
\text { (por } 7 \text { DIAS) } \\
\text { Do } 3^{\circ} \text { dia PO ao } 9^{\circ} \text { dia PO }\end{array}$} & \multirow{2}{*}{$\begin{array}{l}10^{\circ} \text { DIA PO } \\
\text { EUTANÁSIA }\end{array}$} & \multirow[b]{2}{*}{$N=10$} \\
\hline & & ENXERTO & $1^{0} \mathrm{PO}$ & $2^{0} \mathrm{PO}$ & & & \\
\hline EEAV+ & & ENXERTO & $1^{0} \mathrm{PO}$ & $2^{0} \mathrm{PO}$ & EEAV (+) & EUTANÁSIA & $\mathrm{N}=10$ \\
\hline EEAV - & & ENXERTO & $1^{\circ} \mathrm{PO}$ & $2^{0} \mathrm{PO}$ & EEAV (-) & EUTANÁSIA & $\mathbf{N}=10$ \\
\hline Nicotina & NICOTINA & ENXERTO & $1^{\circ} \mathrm{PO}$ & $2^{\circ} \mathrm{PO}$ & & EUTANÁSIA & $N=10$ \\
\hline $\begin{array}{c}\text { Nicotina e } \\
\text { EEAV + }\end{array}$ & NICOTINA & ENXERTO & $1^{0} \mathrm{PO}$ & $2^{0} \mathrm{PO}$ & EEAV (+) & EUTANÁSIA & $\mathrm{N}=10$ \\
\hline $\begin{array}{c}\text { Nicotina e } \\
\text { FFAV - }\end{array}$ & NICOTINA & ENXERTO & $1^{\circ} \mathrm{PO}$ & $2^{0} \mathrm{PO}$ & EEAV (-) & EUTANÁSIA & $\mathrm{N}=10$ \\
\hline
\end{tabular}

Figura 1: Fluxograma do delineamento experimental. 


\subsection{Técnica Operatória}

Para a realização da cirurgia de enxertia, os animais foram anestesiados com injeção intraperitoneal de cloridrato de Cetamina (Agener União ${ }^{\circledR}$, Ribeirão Preto, SP,

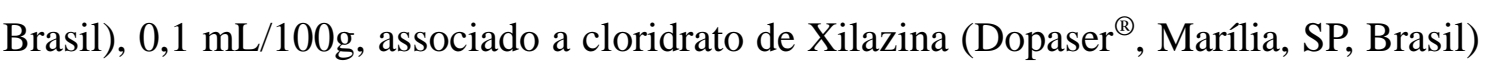
$(0,07 \mathrm{~mL} / 100 \mathrm{~g})$, de acordo com critérios estabelecidos em estudo (Ely e Ferreira, 2003).

Os animais foram imobilizados em prancha cirúrgica para depilação por tração manual, a antissepsia efetuada com álcool 70\%. As áreas cirúrgicas na região dorsal do animal, localizadas abaixo dos ângulos inferiores das escápulas, e a outra $3 \mathrm{~cm}$ abaixo desta (Amâncio et al., 2006), foram demarcadas por um molde de aço inoxidável (2x2 $\mathrm{cm}$ ), especialmente confeccionado para padronização dos enxertos. Em seguida foi efetuada a ressecção da pele até o limite da fáscia muscular, com bisturi lâmina 15 .

A aplicação dos enxertos nas áreas receptoras foi efetuada transpondo as peles das respectivas áreas. A fixação do enxerto foi efetuada com ponto simples de fio de nylon 6.0 nos cantos, e 5.0 ao longo das bordas para melhor fixação do curativo.

Após o procedimento cirúrgico foi aplicada uma lâmina de tecido tipo rayon (Curatec $^{\circledR}$, São Paulo, SP, Brasil), e quatro camadas de gaze sobre o enxerto, seguido de amarração dos fios de calibre 5.0 sobre os curativos (curativo de Brown ou tipo tie over), retirado no terceiro dia pós-operatório (Figura 2). Em seguida, os animais foram identificados e alocados em gaiolas individuais.

Após a cirurgia de enxertia de pele, os animais receberam dipirona (Biovet ${ }^{\circledR}$, São Paulo, SP, Brasil) como analgésico, 1 gota/150 mL (Silveira, 2012). 


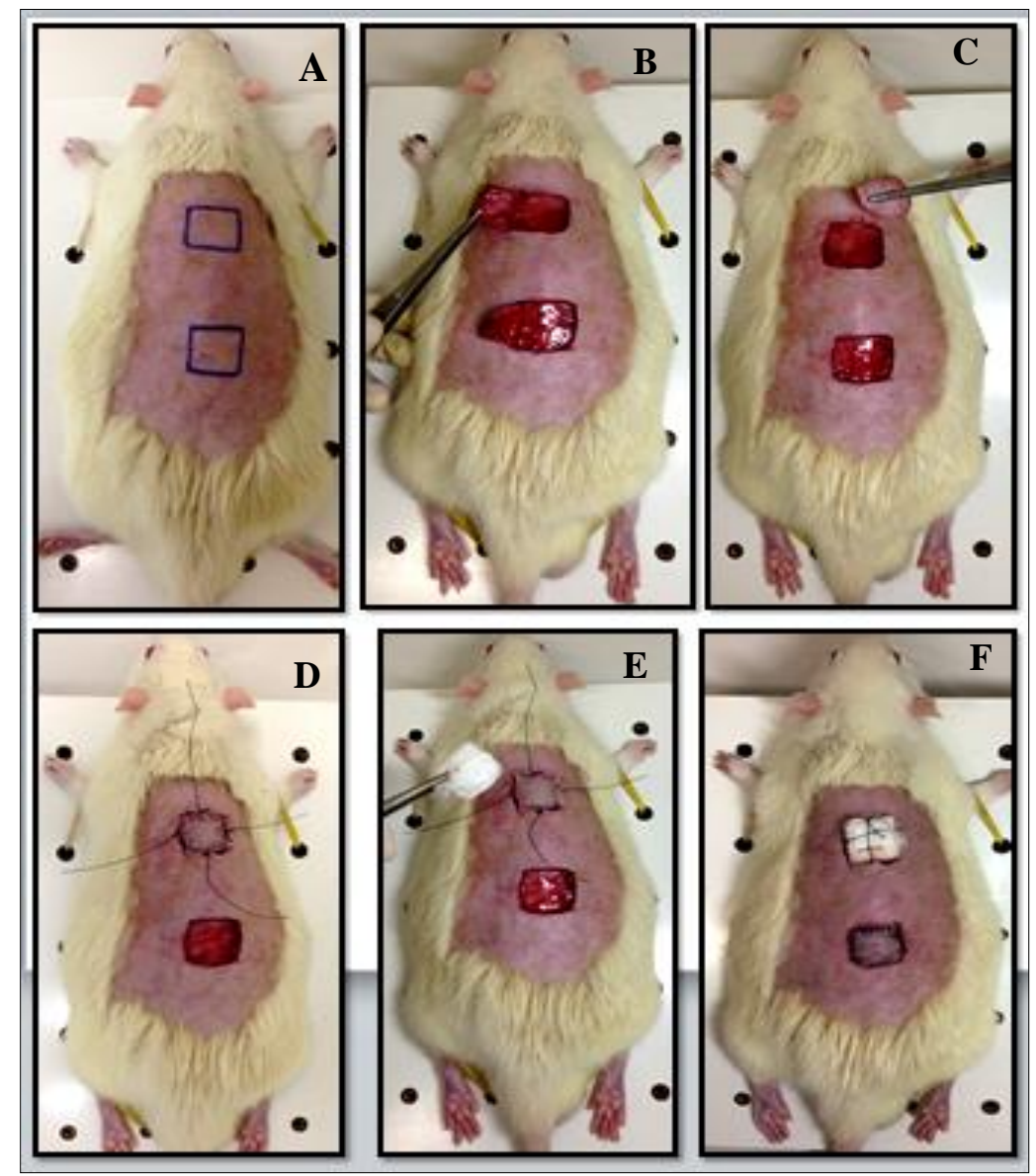

Figura 2 - Esquema ilustrando o procedimento cirúrgico: A - Demarcação do Enxerto com as medidas padrão 2X2; B - Ressecção dos segmentos cutâneos e a colocação destes em soro físiológico; C e D- Aplicação dos enxertos nas áreas receptoras transpondo as peles das respectivas áreas; D: Pontos simples nos 4 vértices e entre eles ponto simples com sobra de linha; E: Aplicação de gaze e curativo Rayon F: Amarração dos fios - Brown ou tipo tie over. (Arquivo pessoal).

\subsection{Procedimento Terapêutico com estimulação elétrica de alta voltagem}

A estimulação elétrica de alta voltagem (EEAV) foi efetuada com o equipamento Neurodyn High Volt - ANVISA 10360310008 - IBRAMED ${ }^{\circledR}$ com timer aferido por meio de três cronômetros Technos ${ }^{\circledR}$ (Figura 3). 
A aplicação da EEAV foi iniciada no terceiro dia após a cirurgia, quando foi retirado o curativo do enxerto, sendo que, foram realizadas sete sessões, com estimulação anódica e catódica, nível motor, por 30 minutos, $10 \mathrm{~Hz}$; voltagem mínima para produzir contração, $20 \mu$ s, e $100 \mu$ s de intervalo de pulso (Cramp et al., 1999).

A intenção terapêutica foi aplicada com eletrodo ativo de alumínio, medindo 2,0X2,0 cm, posicionado sobre um enxerto (enxerto cranial) e, o dispersivo, medindo 4,0X4,0 cm posicionado na região ventral do animal. O eletrodo dispersivo foi devidamente acoplado com esponja embebida em água, e o eletrodo ativo, acoplado com gaze embebida em soro fisiológico estéril.

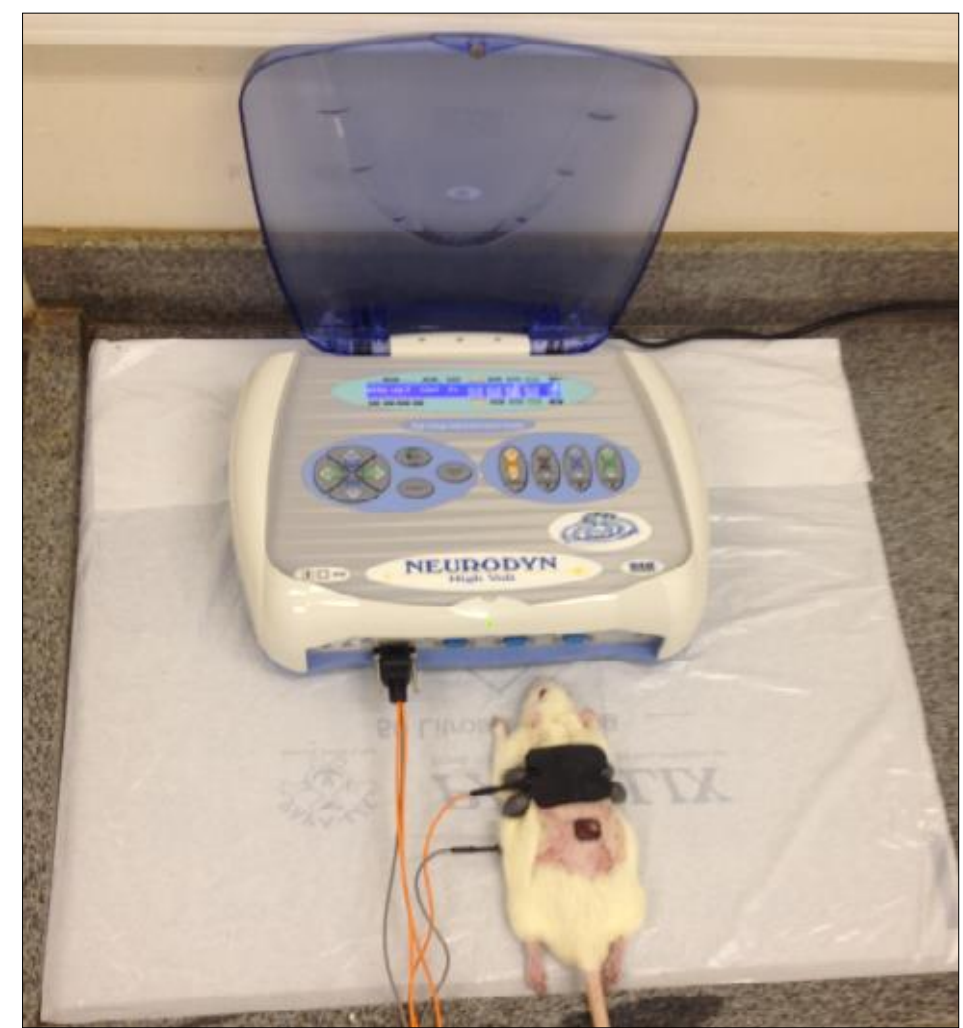

Figura 3- Aplicação do equipamento de Estimulação elétrica de alta voltagem. (Fonte: Arquivo pessoal).

Com intuito de padronizar a pressão do eletrodo sobre o enxerto, foi confeccionado um dispositivo especialmente para a função, constituído de material de velcro e fios de nylon com pesos de chumbo de $200 \mathrm{~g}$ (Figura 4). 


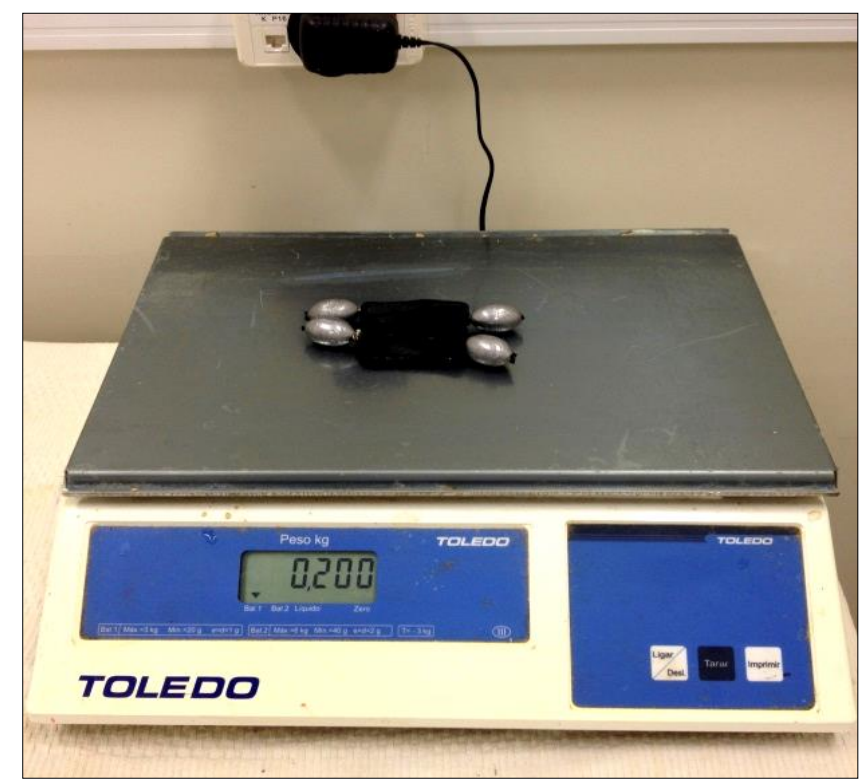

Figura 4- Dispositivo confeccionado para padronização da pressão do eletrodo no enxerto. (Fonte: Arquivo pessoal).

\subsection{Eutanásia do animal}

Os animais foram submetidos à eutanásia no $10^{\circ}$ dia pós-operatório com uma dose excessiva de anestésico (cloridrato de cetamina associado a cloridrato de xilazina) e toda a área enxertada foi retirada, compreendendo um quadrado de pele de $\pm 4 \mathrm{~cm}$ de lado.

\subsection{Análise da porcentagem de contração do enxerto}

A porcentagem de contração do enxerto foi analisada pelo software Image $\mathbf{J}^{\circledR}$ (US National Institutes of Health, Bethesda, Maryland, USA) no $3^{\circ}$ dia e no $10^{\circ}$ dia após a cirurgia (Figura 5). Foi efetuada a média dos valores encontrados nos animais, sendo, o perímetro inicial correspondente aos valores após a cirurgia ( $3^{\circ}$ dia) e perímetro final aos valores do $10^{\circ}$ dia após a cirurgia.

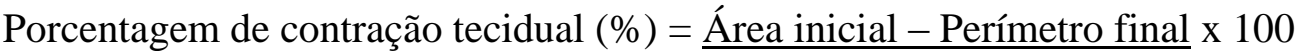

Área inicial 


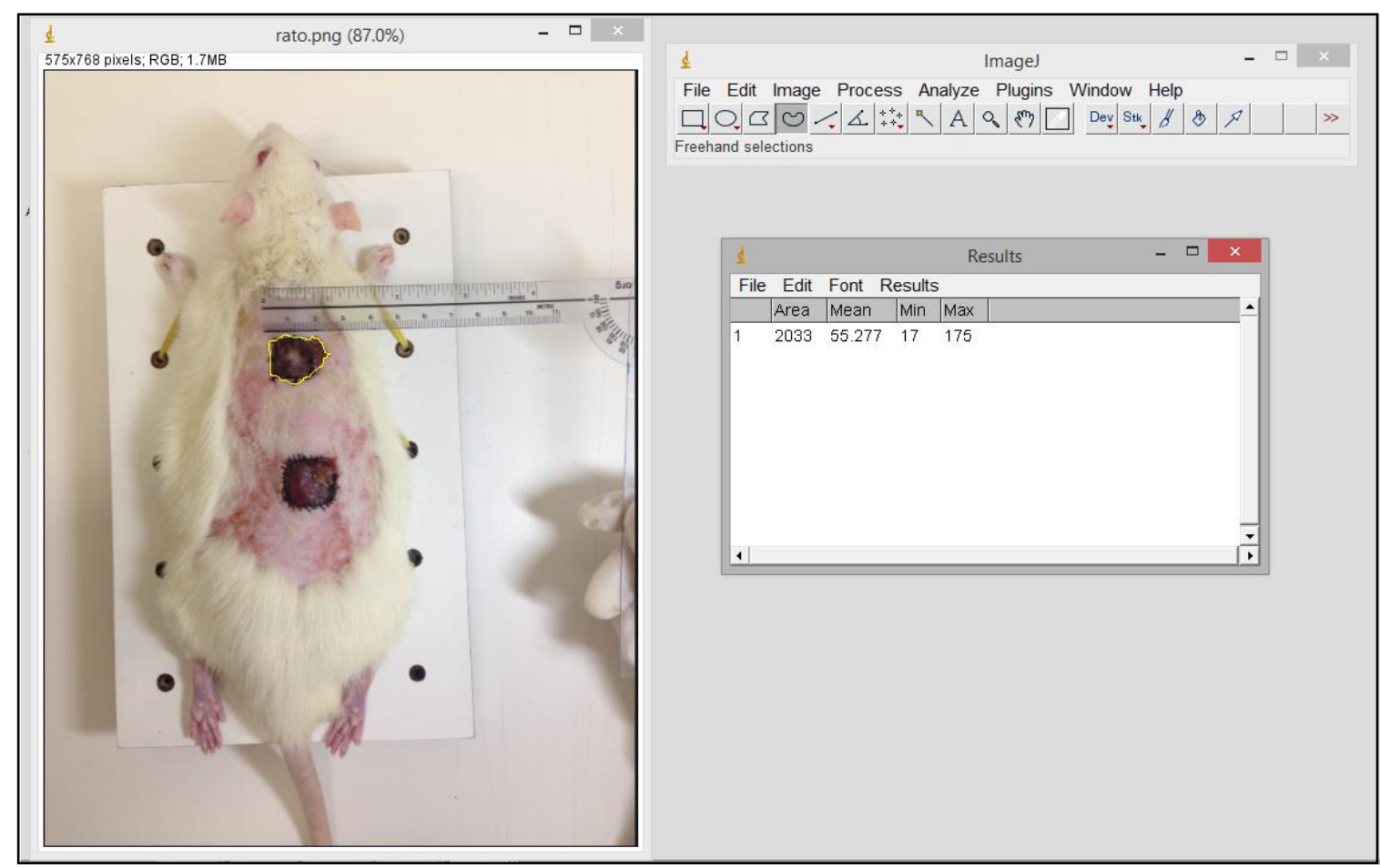

Figura 5- Desenho do enxerto demarcado no software Image $\mathbf{J}^{\circledR}$. (Fonte: Arquivo Pessoal).

\subsection{Termografia infravermelha}

A análise da circulação dos enxertos dos grupos experimentais foi efetuada por meio de equipamento de termografia, marca FLIR ${ }^{\circledR}$ T300 sc: High Temperature Infrared Thermal Imaging Camera 320X240 IR Resolution, Measures Temperature to $1202^{\circ} \mathrm{F}$ $\left(650^{\circ} \mathrm{C}\right), 2 \mathrm{X}$ Continuous Zoom (FLIR ${ }^{\circledR}$ Systems, Wilsonville, OR, EUA).

As análises das imagens infravermelhas foram efetuadas em ambiente com temperatura controlada a $23^{\circ} \mathrm{C}\left( \pm 2^{\circ} \mathrm{C}\right)$, e aclimatação de 15 minutos. As imagens foram avaliadas no período pré-operatório, imediatamente após a cirurgia, no $3^{\circ}$ dia após a cirurgia (após a retirada do curativo). Também foram avaliadas nos seis dias subsequentes antes do procedimento terapêutico com estimulação elétrica de alta voltagem (EEAV), e no $10^{\circ}$ dia, quando os animais foram submetidos à eutanásia. 


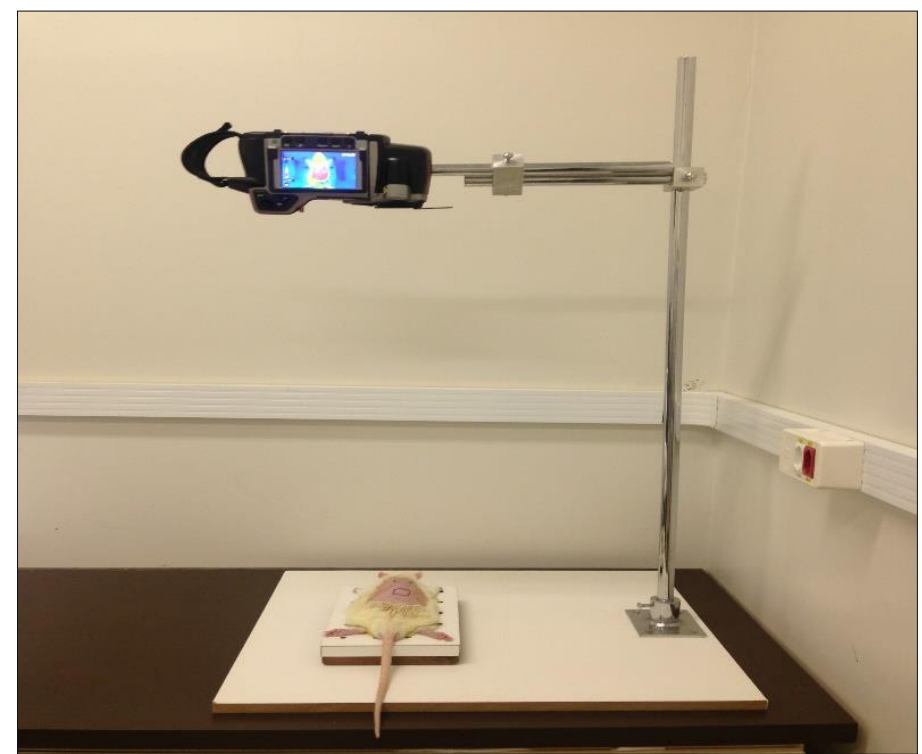

Figura 6- Dispositivo confeccionado para suporte do equipamento de termografia infravermelha.. (Fonte: Arquivo pessoal).

O equipamento foi fixado a uma distância de 80 centímetros do animal, por meio de instrumento confeccionado para padronização das imagens (Figura 6). Marcadores de isopor foram posicionados nos quatro vértices do enxerto para facilitar a identificação no software (Figura 7). Os enxertos foram demarcados no software, que informava a temperatura média do enxerto (Figura 8).

O processamento das imagens infravermelhas foi efetuado pelo software Research IR FLIR ${ }^{\circledR}\left(\right.$ FLIR $^{\circledR}$ Systems, Wilsonville, OR, EUA).

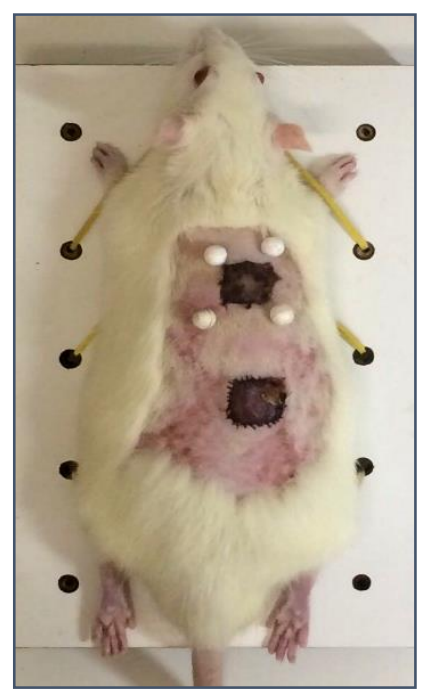

Figura 7- Marcadores de isopor nos quatro vértices do enxerto. Fonte: Arquivo pessoal. 


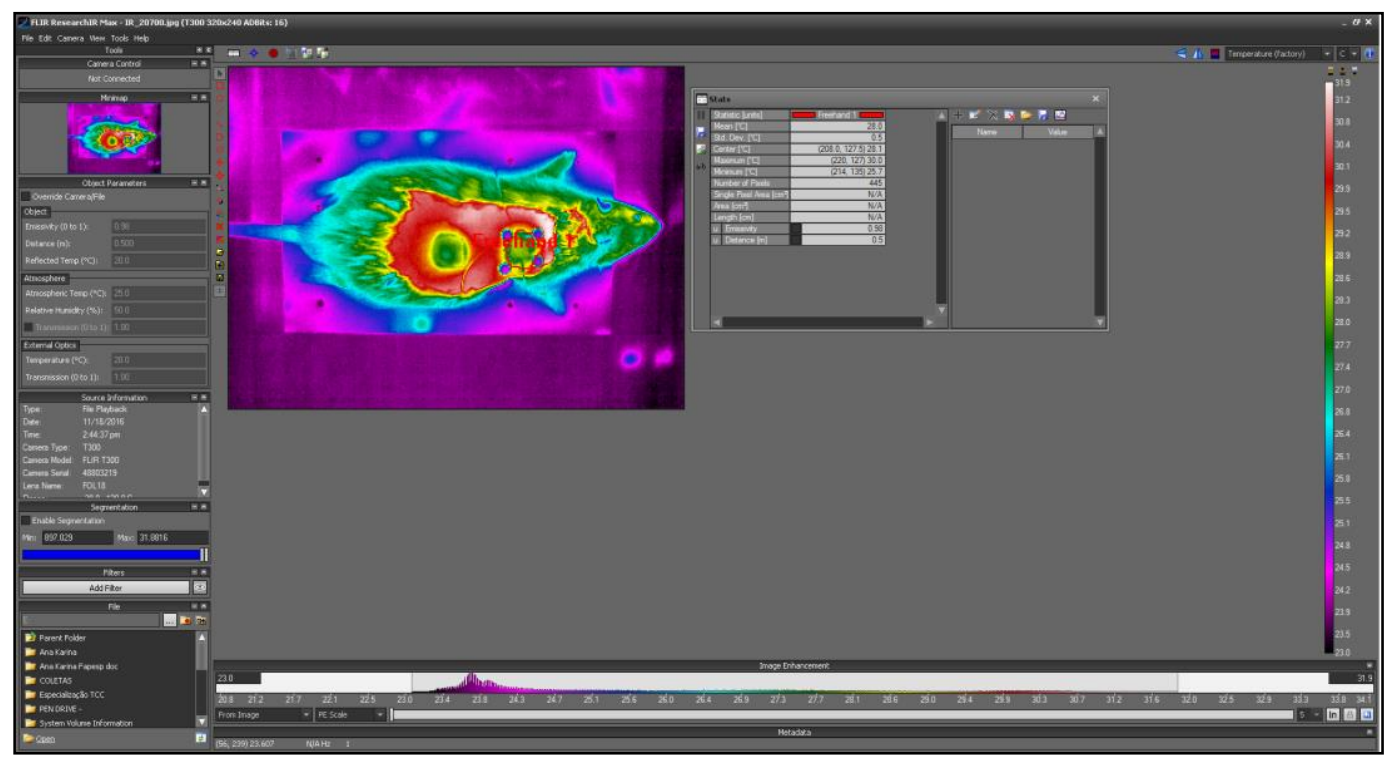

Figura 8 - Enxerto demarcado no software Research IR FLIR ${ }^{\circledR}$ T300 sc (Fonte: Arquivo pessoal).

\subsection{Técnica histológica}

Amostra do enxerto foi coletada para análise histológica, submetida em meio fixador de Formol 10\%, e preparadas para análise histológica. Os procedimentos realizados para preparação das amostras envolveram a fixação, desidratação, diafanização, embebição e a inclusão ou emblocagem. Na fixação, os segmentos de pele foram fixados em solução tamponada de formol a $10 \%$ por 48 horas. A desidratação consistiu-se na passagem da peça em concentrações crescentes de álcool etílico $(50 \%, 70 \%, 90 \%$ e $100 \%)$ com o objetivo de eliminar toda a água contida do material. O processo de diafanização consistiu-se em três trocas de xilol para retirada do álcool da etapa anterior e preparo da peça para a imersão em parafina líquida. Na embebição colocou-se a peça em um recipiente com parafina líquida à temperatura de $56^{\circ} \mathrm{C}$, sendo efetuadas três trocas para que a parafina se infiltrasse em todo o interior da peça e na inclusão ou emblocagem, que foi realizada após a embebição, o material foi incluído em parafina líquida. Em seguida a peça foi encaminhada para microtomia e cortes não seriados com 5$6 \mu \mathrm{m}$ de espessura foram corados por Hematoxilina-Eosina para quantificar a espessura da epiderme dos enxertos, infiltrados inflamatórios e área de gap. 


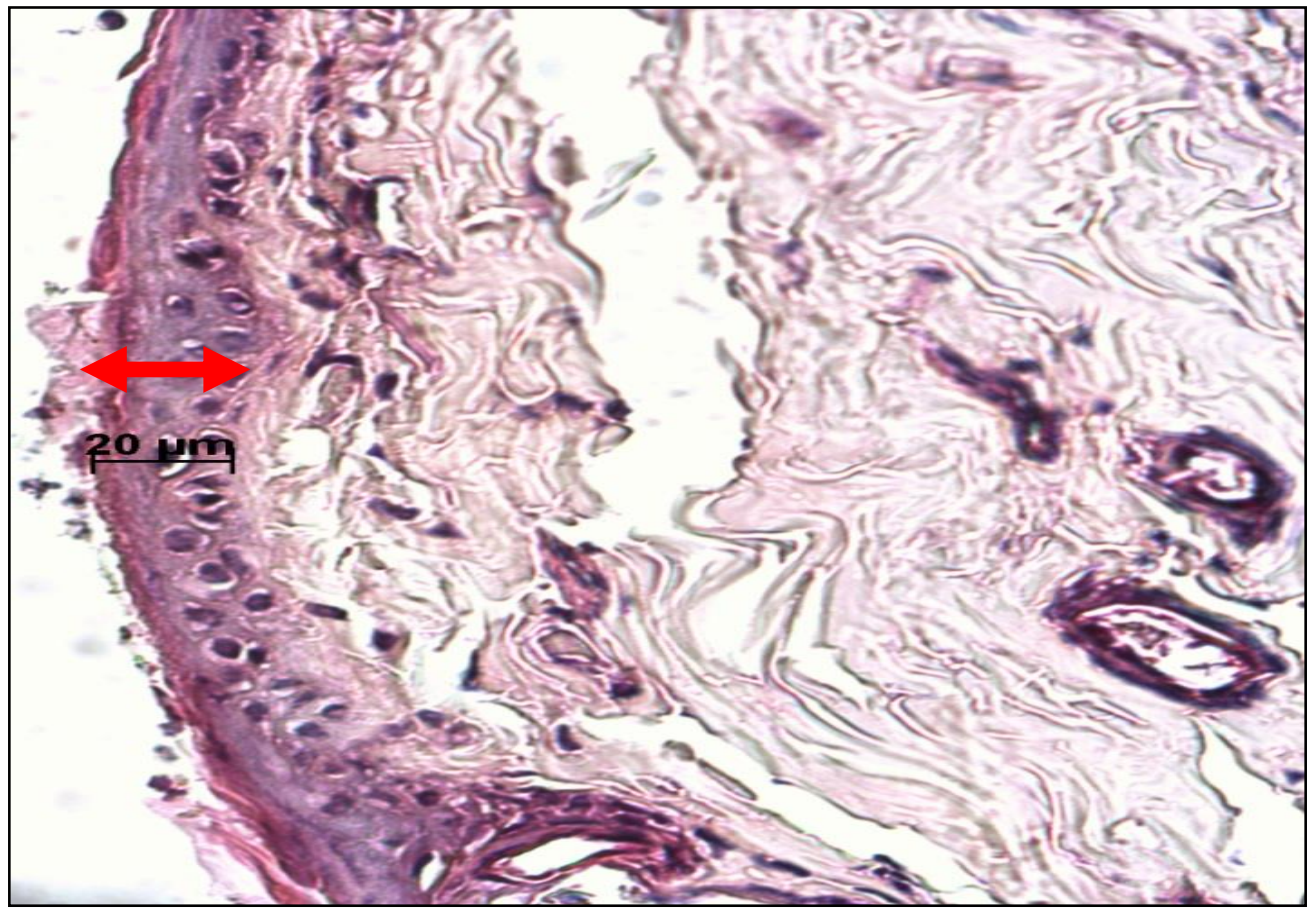

Figura 9 - Imagem microscópica histológica ilustrativa da medida da espessura da epiderme em $\mu \mathrm{m}$ dos enxertos com a coloração Hematoxilina e Eosina - HE. (Fonte: Arquivo Pessoal).

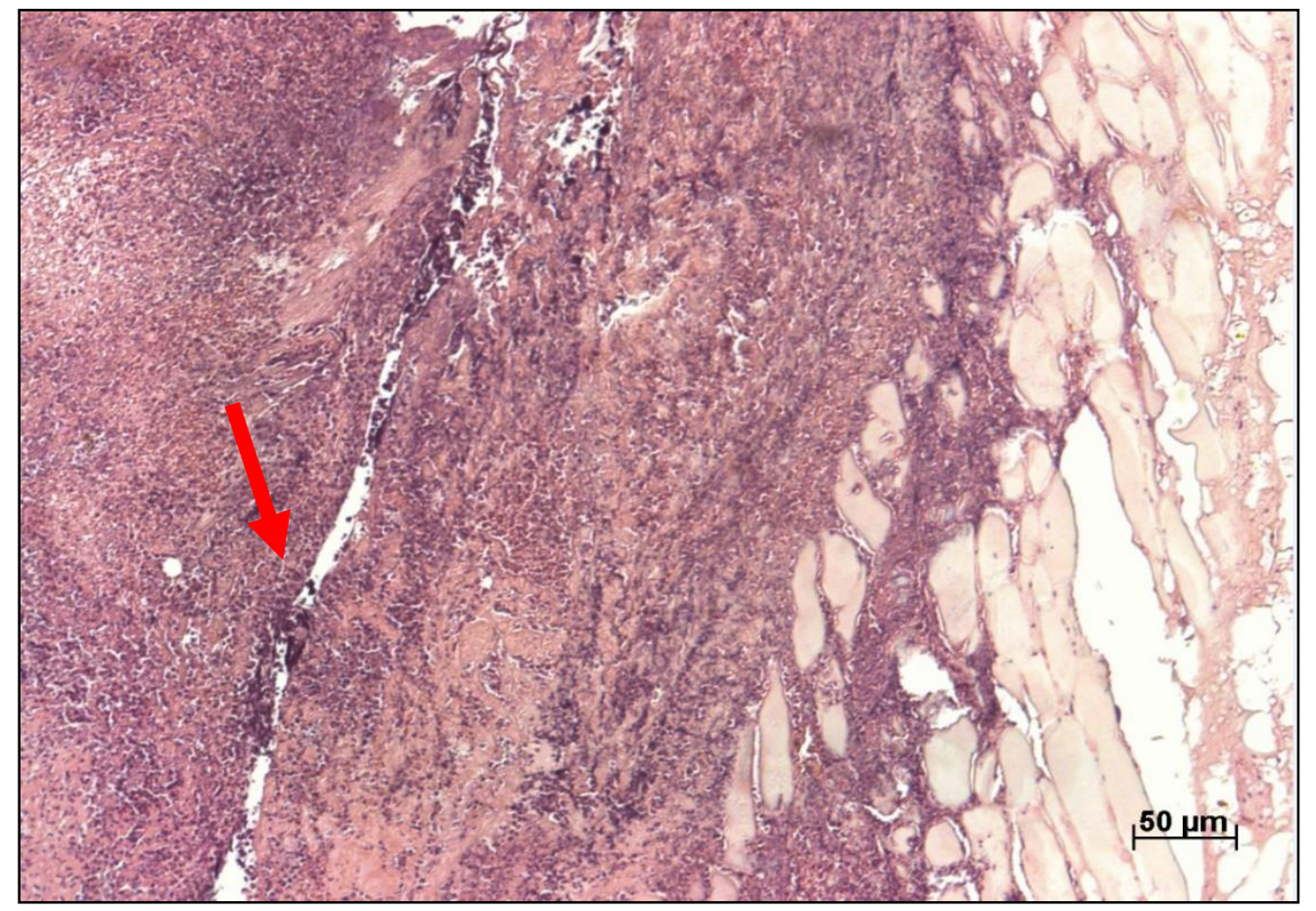

Figura 10 - Imagem microscópica histológica ilustrativa da medida dos infiltrados inflamatórios em $\mu \mathrm{m}$ dos enxertos com a coloração Hematoxilina e Eosina (HE). (Fonte: Arquivo pessoal). 


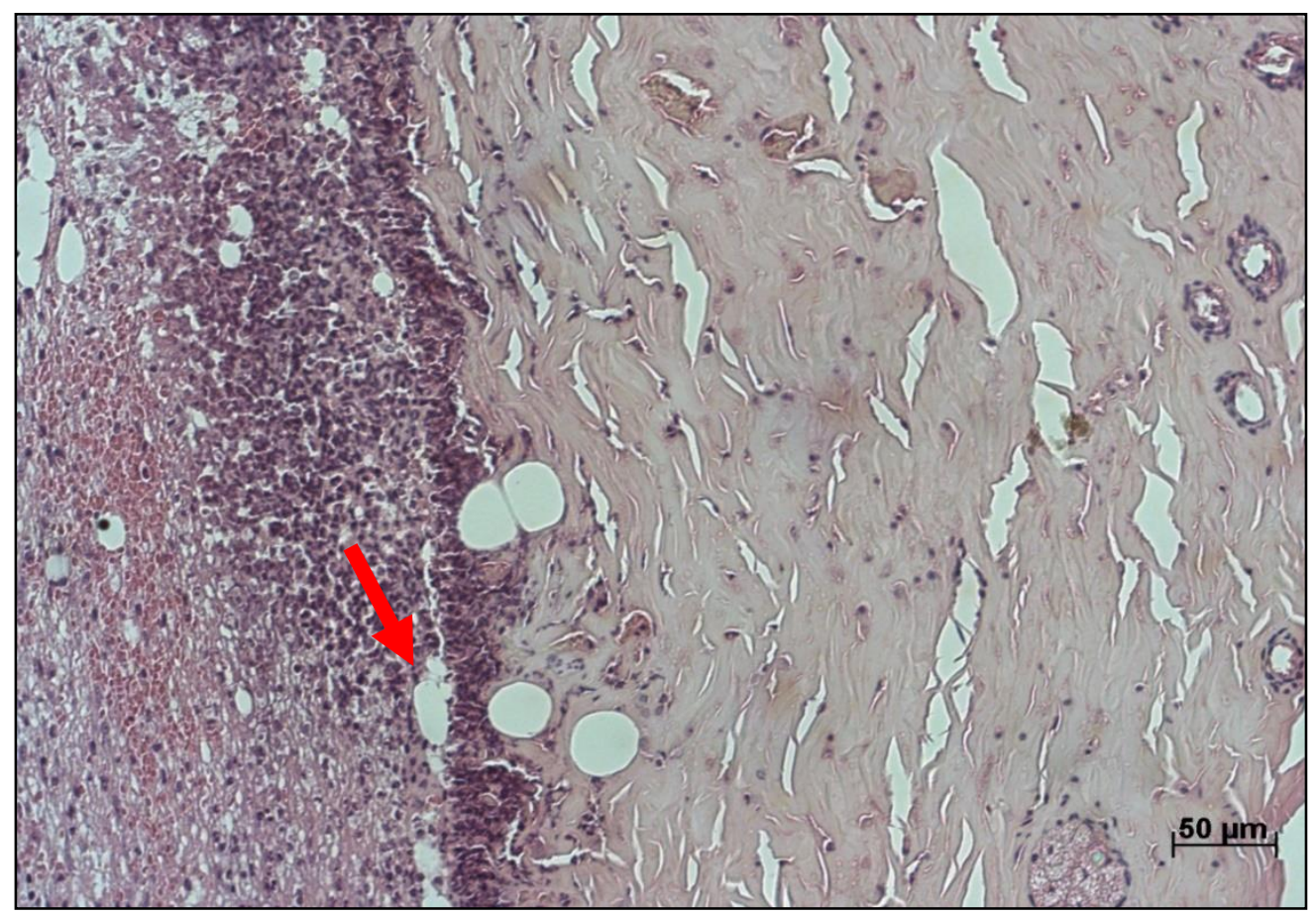

Figura 11 - Imagem microscópica histológica ilustrativa da medida da área de gap do enxerto com a coloração Hematoxilina e Eosina (HE) (Fonte: Arquivo pessoal).

\subsubsection{Morfometrias para avaliação da espessura da epiderme, infiltrados inflamatórios e área de gap}

A leitura das lâminas foi efetuada em microscópio óptico marca Axiostar Plus (Alemanha) com uma câmera ocular Zeiss Axiocam ICc 1 de 10X e objetiva de 40X totalizando um aumento de 400X, com avaliador cegado para o grupo de lâminas examinado. Para leitura morfométrica foram observados cinco campos em cada lâmina.

\subsection{Análise Imunohistoquímica}

As reações de imunohistoquímica foram efetuadas em cortes histológicos do material parafinado por meio da reação antígeno-anticorpo seguida da reação com marcador visível ao microscópio. As lâminas desparafinadas e hidratadas 
passaram por um processo de recuperação antigênica por incubação em panela a vapor em meio tamponado por 40 minutos. Após resfriamento do material, as peroxidases teciduais endógenas foram removidas pela adição de peróxido de hidrogênio, e ligações inespecíficas do anticorpo primário foram evitadas por adição de soro de cavalo. As lâminas foram então incubadas com anticorpo primário para Anti-VEGFA e Anti-fator VIII, incubados por 12 horas (over night) em câmara úmida. Em seguida, as lâminas foram incubadas com anticorpo secundário por 30 minutos, seguindo para o polímero conjugado também por 30 minutos, e corou-se com DAB por 1 minuto; todos do Kit PicTure ${ }^{T M}$ MAX Polymer (ZYMED ${ }^{\circledR}$ Laboratories). As lâminas foram contra-coradas com Hematoxilina de Harris por 1 minuto e montadas com Entelan para posteriores análises em microscopia de luz.

\subsubsection{Morfometrias para avaliação do fator de crescimento do endotélio vascular (VEGF) e vasos sanguíneos (Fator VIII)}

A leitura das lâminas foi efetuada em microscópio óptico marca Axiostar Plus (Alemanha) com uma lente ocular Zeiss Axiocam ICc 1 de 10X e objetiva de 40X totalizando um aumento de 400X, com avaliador cegado para o grupo de lâminas examinado. Para leitura morfométrica foram observados cinco campos em cada lâmina. 

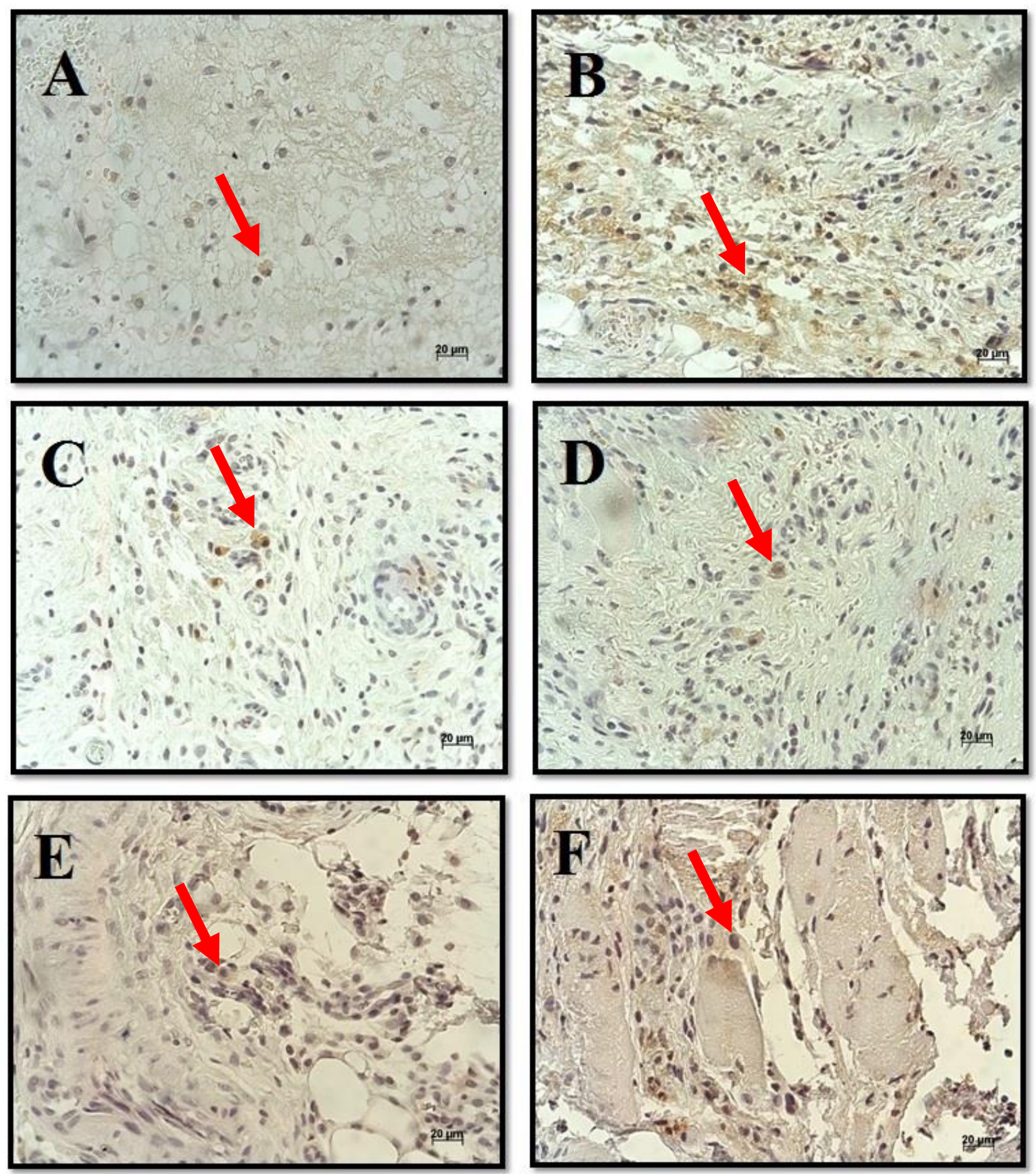

Figura 12- Fotomicrografias da imunomarcação de anticorpo primário para Anti-VEGFA. Representação dos grupos: A - Grupo 1; B - Grupo 2; C - Grupo 3; D - Grupo 4; E - Grupo 5; F- Grupo 6. (Fonte: Arquivo pessoal). 

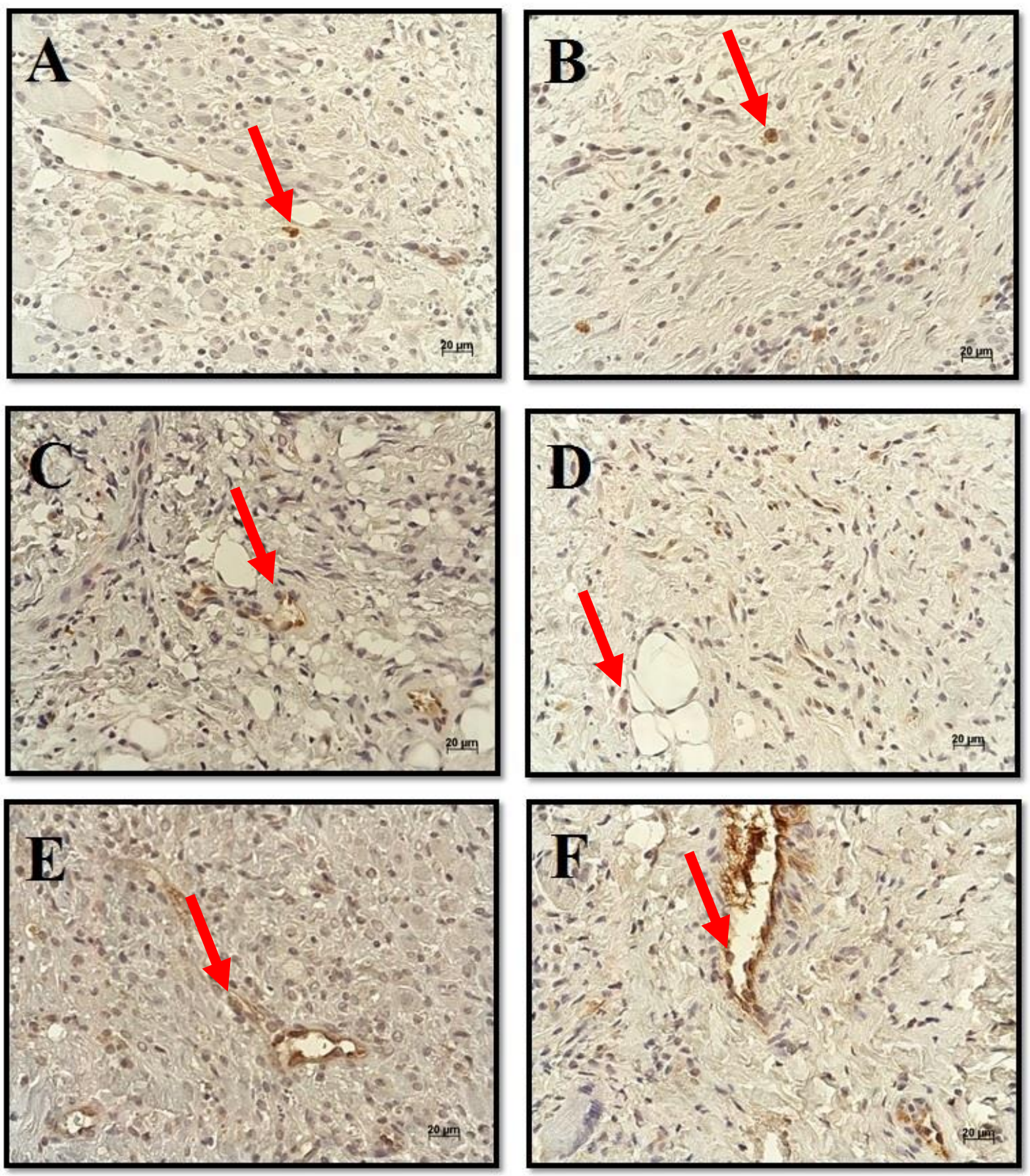

Figura 13- Fotomicrografias da imunomarcação de anticorpo primário para Anti-fator VIII. Representação dos grupos: A - Grupo 1; B - Grupo 2; C - Grupo 3; D - Grupo 4; E Grupo 5; F- Grupo 6. (Fonte: Arquivo pessoal). 


\subsection{Análise estatística}

Para a análise estatística da temperatura cutânea por meio da termografia infravermelha, foi utilizado o modelo linear com efeitos mistos para a proporção $\mathrm{p}=\frac{\text { Dia } \mathrm{i}}{\text { Dia } 1}$ sendo $\mathrm{i}=$ dias avaliados.

Os dados referentes a porcentagem de contração do enxerto, espessura da epiderme, espessura dos infiltrados inflamatórios, área de GAP, VEGF e Fator VIII, foram tratados com ANOVA com pós-teste de Dunkan.

O processamento dos dados foi efetuado pelo software SAS (Cary, NC), versão 9.3 sendo fixado o nível crítico de $5 \%(\mathrm{p}<0,05)$. 
Resultados 


\section{RESULTADOS}

\subsection{Valores percentuais de contração do enxerto cutâneo}

Os dados referentes a porcentagem de contração do enxerto (Image $\mathbf{J}^{\circledR}$ ) entre os grupos foram avaliados pelo teste ANOVA e post-hoc de Dunkan, com valor de $\mathrm{F}_{5,54}=$ 4,284 e $\mathrm{p}<0,005$, sendo observada diferença significativa $(\mathrm{p}<0.05)$ entre o grupo 4 , quando comparado com os grupos 1,2,3,5 e 6, que apresentou maior porcentagem de contração da área do enxerto (Tabela 1).

Tabela 1 - Valores das porcentagens média e desvios-padrão de contração do enxerto nos grupos estudados $(\%)$.

$$
\text { Média } \pm \text { DP }
$$

\begin{tabular}{lc}
\hline Grupo 1 - Sham & $11,1 \pm 5,52$ \\
\hline Grupo 2 - EEAV + & $8,9 \pm 3,67$ \\
\hline Grupo 3 - EEAV- & $9,2 \pm 4,27$ \\
\hline Grupo 4 - Nicotina & $16,6 \pm 5,09^{*}$ \\
\hline Grupo 5 - Nicotina e EEAV + & $10,6 \pm 3,10$ \\
\hline Grupo 6 - Nicotina e EEAV- & $12,6 \pm 3,73$ \\
\hline $\begin{array}{l}\text { DP - Desvio-Padrão } \\
\text { EEAV + - Estimulação elétrica de alta voltagem anódica } \\
\text { EEAV - - Estimulação elétrica de alta voltagem catódica } \\
{ }^{*} \text { p } \leq 0.05 \text { vs grupo 1, 2, 3, } 5 \text { e } 6\end{array}$
\end{tabular}




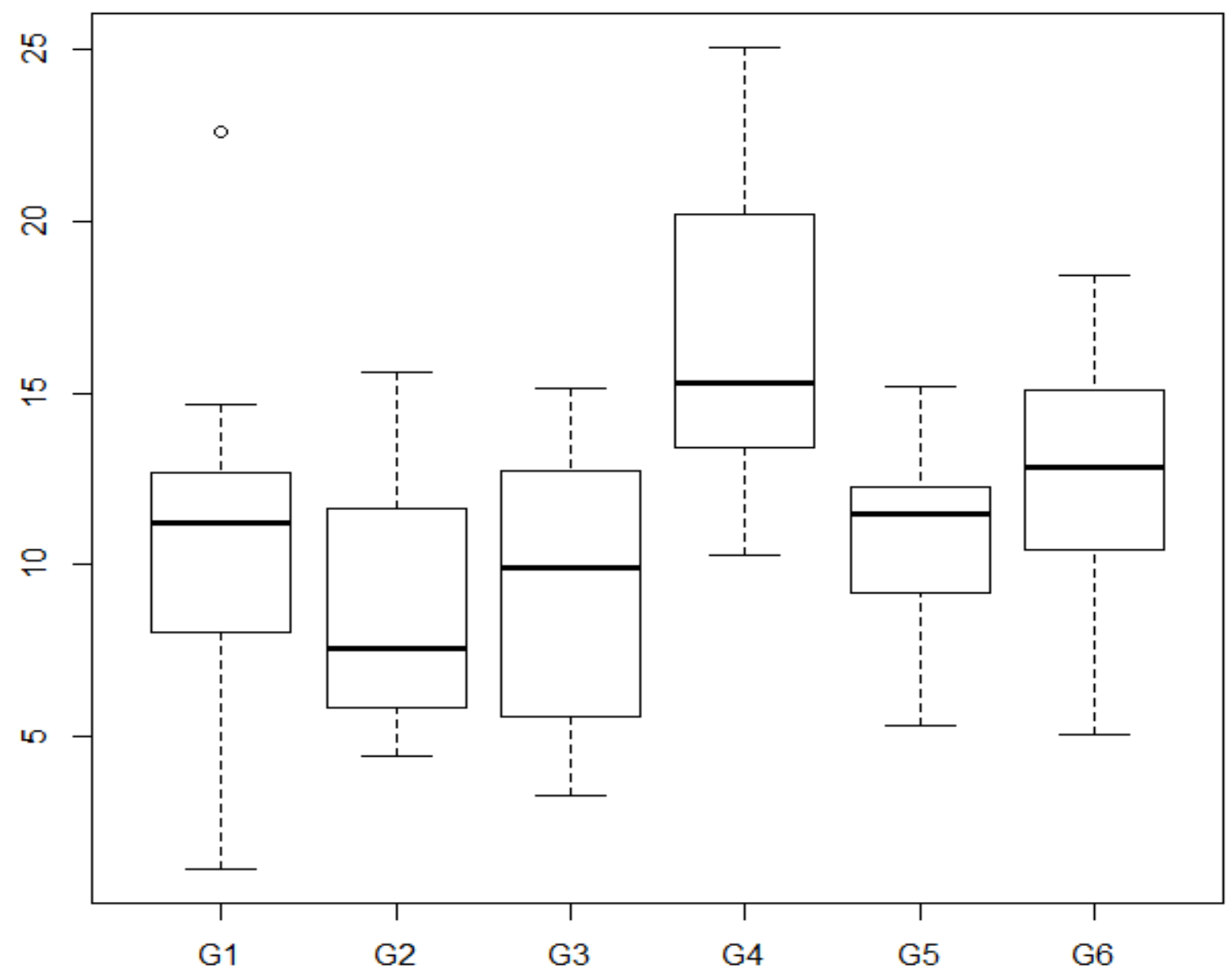

Figura 14 - Gráfico em Box-plot da porcentagem de contração do enxerto cutâneo, ilustrando a mediana (-), valor mínimo e máximo (-), $1^{\circ}$ e $3^{\circ}$ quartil (borda inferior e superior do retângulo). Grupo 1- Sham; Grupo 2- EEAV+; Grupo 3 - EEAV-; Grupo 4- Nicotina; Grupo 5 - Nicotina e EEAV +; Grupo 6 Nicotina e EEAV -.

\subsection{Valores da temperatura dos enxertos obtidos pela Termografia}

A termografia foi avaliada no período pré-operatório, imediatamente após a cirurgia, no $3^{\circ}$ dia após a cirurgia (após a retirada do curativo), nos seis dias subsequentes, e no $10^{\circ}$ dia, quando os animais foram submetidos à eutanásia. Os resultados obtidos relativos a temperatura cutânea média dos enxertos avaliados pela termografia estão demonstrados na Tabela 2 nos grupos estudados. Todas as avaliações foram realizadas pré-aplicação do recurso terapêutico. 
Tabela 2 - Valores das temperaturas médias e desvios-padrão dos enxertos nos grupos estudados $\left({ }^{\circ} \mathrm{C}\right)$ de acordo com os dias avaliados.

\begin{tabular}{|c|c|c|c|c|c|c|}
\hline & $\begin{array}{c}\text { Grupo } 1 \\
\text { (Sham) }\end{array}$ & $\begin{array}{l}\text { Grupo } 2 \\
\text { EEAV + }\end{array}$ & $\begin{array}{l}\text { Grupo } 3 \\
\text { EEAV - }\end{array}$ & $\begin{array}{l}\text { Grupo } 4 \\
\text { Nicotina }\end{array}$ & $\begin{array}{c}\text { Grupo } 5 \\
\text { Nicotina e EEAV } \\
+ \\
\end{array}$ & $\begin{array}{c}\text { Grupo 6 } \\
\text { Nicotina e EEAV } \\
-\end{array}$ \\
\hline Pré-operatório & $33,21 \pm 0,66$ & $32,65 \pm 1,45$ & $31.84 \pm 0,60$ & $32,26 \pm 0,89$ & $32,53 \pm 1,00$ & $31,34 \pm 0,81$ \\
\hline Pós-operatório & $26,11 \pm 2,15^{\#}$ & $28,23 \pm 0,82^{\beta}$ & $28,08 \pm 0,88^{£}$ & $28,03 \pm 0,42^{*}$ & $28,93 \pm 0,64^{\Omega}$ & $28,33 \pm 0,62^{\infty}$ \\
\hline $3^{\circ}$ dia & $33,01 \pm 0,93^{\#}$ & $33,00 \pm 0,34$ & $32,88 \pm 0,69$ & $31,68 \pm 3,81^{*}$ & $31,31 \pm 3,15^{\Omega}$ & $32,49 \pm 0,56$ \\
\hline $4^{\circ}$ dia & $33,70 \pm 0,76$ & $33,42 \pm 0,62$ & $32,36 \pm 0,90$ & $33,00 \pm 0,51$ & $32,01 \pm 0,96^{\Omega}$ & $32,61 \pm 0,78$ \\
\hline $5^{\circ}$ dia & $33,60 \pm 0,57$ & $32,84 \pm 1,48$ & $32,82 \pm 0,75$ & $32,71 \pm 0,65$ & $32,00 \pm 0,63^{\Omega}$ & $32,55 \pm 1,51$ \\
\hline $6^{\circ}$ dia & $33,02 \pm 0,68^{\#}$ & $33,63 \pm 0,84$ & $31,92 \pm 0,59$ & $32,69 \pm 0,53$ & $32,23 \pm 0,69^{\Omega}$ & $32,76 \pm 0,71^{\infty}$ \\
\hline $7^{\circ}$ dia & $32,90 \pm 0,93^{\#}$ & $34,01 \pm 0,74$ & $32,09 \pm 0,84$ & $32,27 \pm 0,65$ & $32,16 \pm 0,58^{\Omega}$ & $31,30 \pm 1,23^{\infty}$ \\
\hline $8^{\circ}$ dia & $33,43 \pm 0,43$ & $33,00 \pm 0,89$ & $31,98 \pm 0,66$ & $31,94 \pm 1,12^{*}$ & $31,76 \pm 0,69^{\Omega}$ & $31,91 \pm 0,68$ \\
\hline $9^{\circ}$ dia & $33,50 \pm 0,80$ & $33,26 \pm 0,94$ & $31,44 \pm 0,58^{\mathfrak{f}}$ & $31,55 \pm 0,80^{*}$ & $31,98 \pm 0,95^{\Omega}$ & $32,05 \pm 0,4$ \\
\hline $10^{\circ}$ dia & $32,40 \pm 0,82^{\#}$ & $33.54 \pm 0,81$ & $32,38 \pm 0,91$ & $31,91 \pm 0,76^{*}$ & $31,75 \pm 0,71^{\Omega}$ & $32,12 \pm 1,22$ \\
\hline
\end{tabular}

DP - Desvio-Padrão

EEAV + - Estimulação elétrica de alta voltagem anódica

EEAV - - Estimulação elétrica de alta voltagem catódica

\#p $\leq 0.05$ vs Grupo $1 \quad \Omega \mathrm{p} \leq 0.05$ vs Grupo 5

$\quad{ }^{\beta} \mathrm{p} \leq 0.05$ vs Grupo $2 \quad{ }^{\infty} \mathrm{p} \leq 0.05$ vs Grupo 6

${ }^{£} \mathrm{p} \leq 0.05$ vs Grupo 3

* $\mathrm{p} \leq 0.05$ vs Grupo 4 
A Figura 15 demonstra o comportamento da temperatura ao longo do tempo.

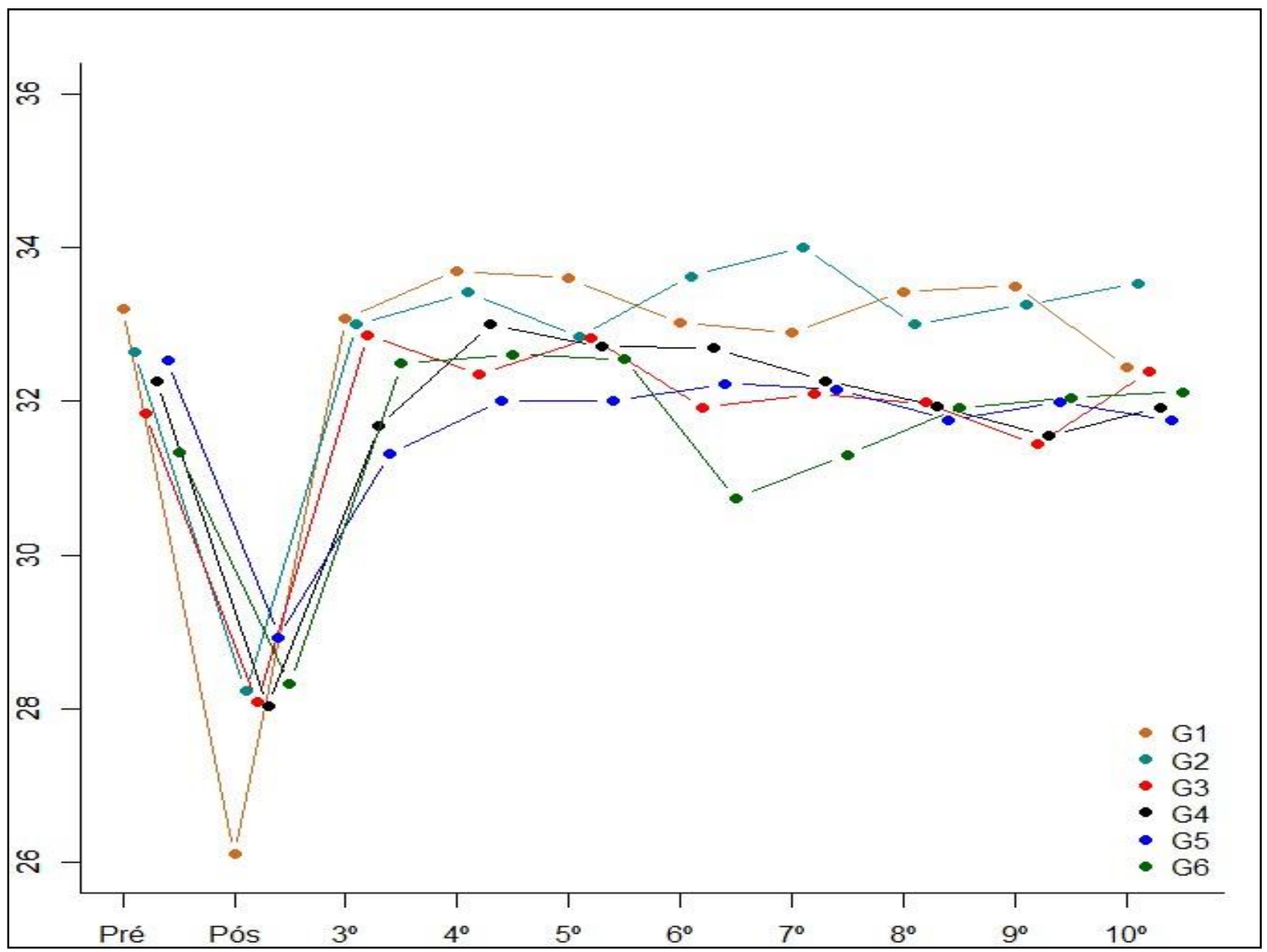

Figura 15 - Comportamento da temperatura ao longo do tempo para os diferentes grupos de acordo com os dias avaliados. Grupo 1 - Sham; Grupo 2- EEAV+; Grupo 3 - EEAV-; Grupo 4- Nicotina; Grupo 5 - Nicotina e EEAV +; Grupo 6 - Nicotina e EEAV -.

A análise da temperatura cutânea foi efetuada por modelo linear com efeitos mistos com valor de $F_{5,54}=3.745$ e $p<0,05$. A comparação de cada grupo, nos diferentes dias avaliados, demonstrou que o Grupo 1 (Sham) apresentou diferença significativa $(\mathrm{p} \leq 0.05)$ no pós-operatório, terceiro, sexto, sétimo e décimo dia, apresentando redução da temperatura no pós-operatório, e aumento da mesma a partir do terceiro dia. O Grupo $2($ EEAV+) apresentou diferença significativa $(p \leq 0.05)$ no período pós-operatório também com uma redução no valor da temperatura. O Grupo 3 $($ EEAV-) apresentou diferença significativa $(\mathrm{p} \leq 0.05)$ no período pós-operatório e nono 
dia, apresentando redução da temperatura no pós-operatório e aumento do valor no nono dia.

O Grupo 4 (nicotina) apresentou diferença significativa $(\mathrm{p} \leq 0.05)$ no pósoperatório, terceiro, oitavo, nono e décimo dia, apresentando um menor valor da temperatura no pós-operatório quando comparado com os demais dias. Já o Grupo 5 apresentou a diferença significativa quando comparado a todos os dias avaliados, demonstrando uma redução da temperatura no período pós-operatório e aumento do valor da mesma no decorrer dos dias até o sétimo dia; a partir do oitavo dia, esta teve uma pequena redução de valor.

Também foi encontrada diferença significativa no Grupo 6 (Nicotina e EEAV-) $(\mathrm{p} \leq 0.05)$ quando comparado ao pós-operatório, sexto e sétimo dia. No período pós-operatório teve uma redução da temperatura, aumento no sexto dia e redução no sétimo.

$\mathrm{Na}$ comparação entre os grupos, foi observado que no terceiro dia pósoperatório foi encontrado uma diferença significativa $(\mathrm{p} \leq 0.05)$ do Grupo 1 em relação ao Grupo 5, este apresentando menor temperatura, e em relação ao Grupo 6, este apresentando maior temperatura. O Grupo 2 apresentou uma diferença significativa $(\mathrm{p} \leq 0.05)$ de maior temperatura quando comparado ao Grupo 5. O Grupo 3 apresentou diferença significativa $(\mathrm{p} \leq 0.05)$ de maior temperatura quando comparado com os Grupo 4 e 5 . Os Grupos 4 e 5 apresentaram uma diferença significativa $(p \leq 0.05)$ quando comparado ao Grupo 6, sendo este apresentando uma maior temperatura.

Quando avaliado o décimo dia (eutanásia), foi observado que o Grupo 1 apresentou diferença significativa $(\mathrm{p} \leq 0.05)$ quando comparado ao Grupo 2, sendo este apresentando uma maior temperatura. O Grupo 2 apresentou uma diferença significativa de maior temperatura $(\mathrm{p} \leq 0.05)$ quando comparado aos Grupos 3, 4, 5 e 6 . 


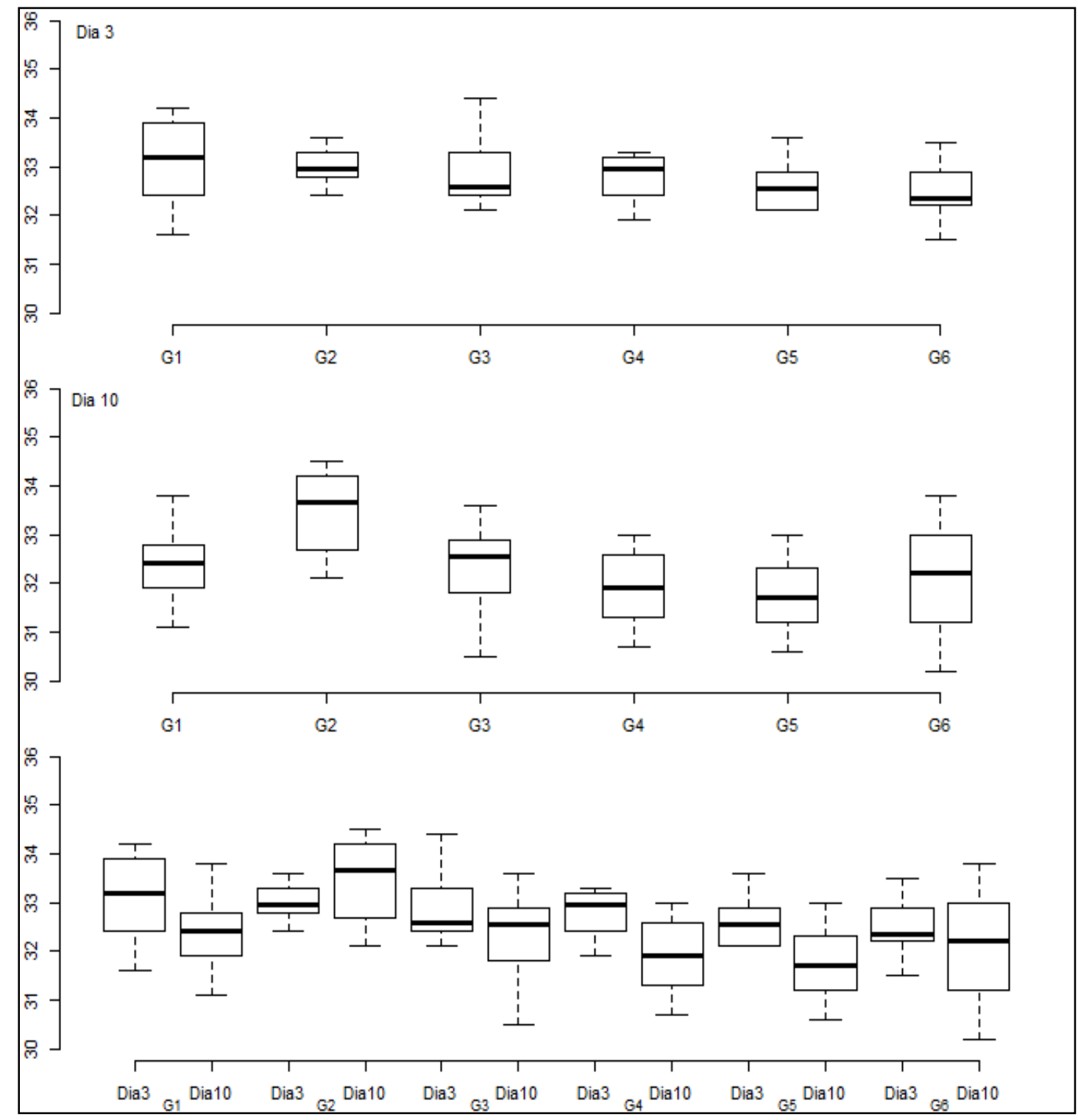

Figura 16 - Gráfico em Box-plot da temperatura do terceiro (Dia 3) e décimo dia (Dia 10), ilustrando a mediana (-), valor mínimo e máximo $(-), 1^{\circ}$ e $3^{\circ}$ quartil (borda inferior e superior do retângulo). Grupo 1- Sham; Grupo 2- EEAV+; Grupo 3 - EEAV-; Grupo 4- Nicotina; Grupo 5 - Nicotina e EEAV +; Grupo 6 - Nicotina e EEAV -. 


\subsection{Valores da espessura da epiderme do enxerto}

Os dados referentes à espessura da epiderme do enxerto entre os grupos foram avaliados pelo teste ANOVA e post-hoc de Dunkan, com valor de F5,54= 4,284 e $\mathrm{p}<0,005$, observou-se que não houve diferença significativa entre os grupos nos dias avaliados (Tabela 3).

Tabela 3 - Valores médios da espessura da epiderme e desvios-padrão do enxerto nos grupos estudados $(\mu \mathrm{m})$.

\begin{tabular}{ll}
\hline & Média \pm DP \\
\hline Grupo 1 - Sham & $1,1 \pm 0,33$ \\
\hline Grupo 2 - EEAV + & $1,2 \pm 0,33$ \\
\hline Grupo 3 - EEAV- & $1,2 \pm 0,36$ \\
\hline Grupo 4 - Nicotina & $1,3 \pm 0,55$ \\
\hline Grupo 5 - Nicotina e EEAV + & $1,5 \pm 0,31$ \\
\hline Grupo 6 - Nicotina e EEAV- & $1,2 \pm 0,17$ \\
\hline
\end{tabular}

DP - Desvio-Padrão

EEAV + - Estimulação elétrica de alta voltagem anódica

EEAV - - Estimulação elétrica de alta voltagem catódica 


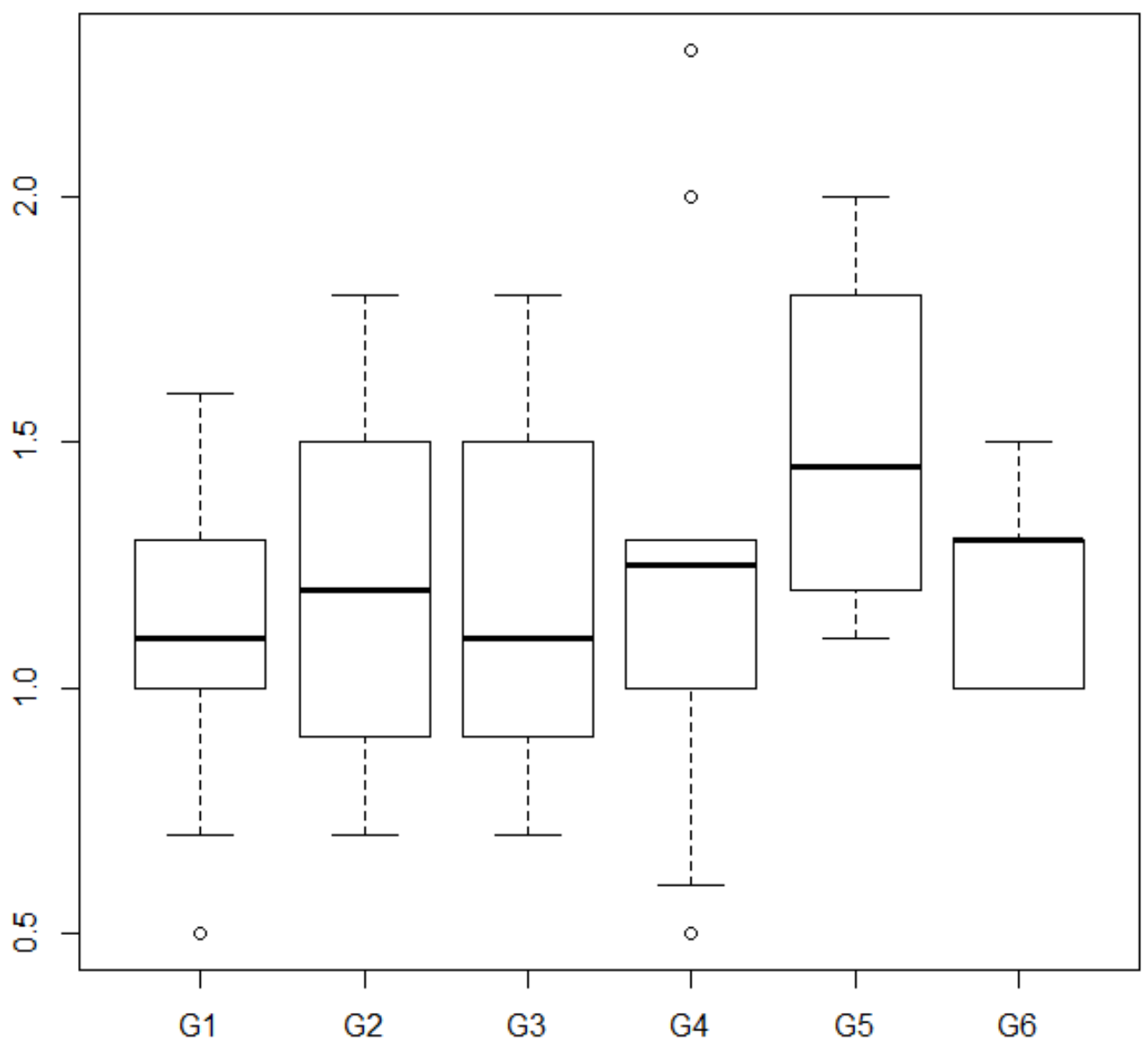

Figura 17 - Gráfico em Box-plot da espessura da epiderme, ilustrando a mediana (-), valor mínimo e máximo $(-), 1^{\circ}$ e $3^{\circ}$ quartil (borda inferior e superior do retângulo). Grupo 1-Sham; Grupo 2- EEAV+; Grupo 3 - EEAV-; Grupo 4- Nicotina; Grupo 5 - Nicotina e EEAV +; Grupo 6 - Nicotina e EEAV -. 


\subsection{Valores da espessura dos infiltrados inflamatórios}

Os dados referentes a espessura dos infiltrados inflamatórios do enxerto entre os grupos foram avaliados pelo teste ANOVA e post-hoc de Dunkan, com valor de $F_{5,54}=4,284$ e $\mathrm{p}<0,005$. Foi observada diferença significativa $(\mathrm{p}<0.05)$ entre os grupos 1,5 e 6 quando comparados com os Grupos 2, 3 e 4, dos Grupos 2 e 3 quando comparado aos grupos 1, 4, 5 e 6, e do Grupo 4 quando comparado a todos os grupos (Tabela 4).

Tabela 4 - Valores médios da espessura dos infiltrados inflamatórios e desvios-padrão do enxerto nos grupos estudados $(\mu \mathrm{m})$.

\begin{tabular}{|c|c|}
\hline & Média \pm DP \\
\hline Grupo 1 - Sham & $115,5 \pm 8,9^{\#}$ \\
\hline Grupo 2 - EEAV + & $89,1 \pm 9,03^{\beta}$ \\
\hline Grupo 3 - EEAV- & $94,7 \pm 8,7^{\beta}$ \\
\hline Grupo 4 - Nicotina & $140,7 \pm 13,65^{£}$ \\
\hline Grupo 5 - Nicotina e EEAV + & $121,5 \pm 14,44^{\#}$ \\
\hline Grupo 6 - Nicotina e EEAV- & $127,5 \pm 13,11^{\#}$ \\
\hline \multicolumn{2}{|l|}{ DP - Desvio-Padrão } \\
\hline \multicolumn{2}{|c|}{ EEAV + - Estimulação elétrica de alta voltagem anódica } \\
\hline \multicolumn{2}{|c|}{ EEAV - - Estimulação elétrica de alta voltagem catódica } \\
\hline \multicolumn{2}{|l|}{${ }^{*} \mathrm{p} \leq 0.05$ vs Grupos 2,3 e 4} \\
\hline \multicolumn{2}{|l|}{${ }^{\beta} \mathrm{p} \leq 0.05$ vs Grupos $1,4,5$ e 6} \\
\hline${ }^{{ }} \mathrm{p} \leq 0.05$ vs Grupos $1,2,3,5$ e 6 & \\
\hline
\end{tabular}




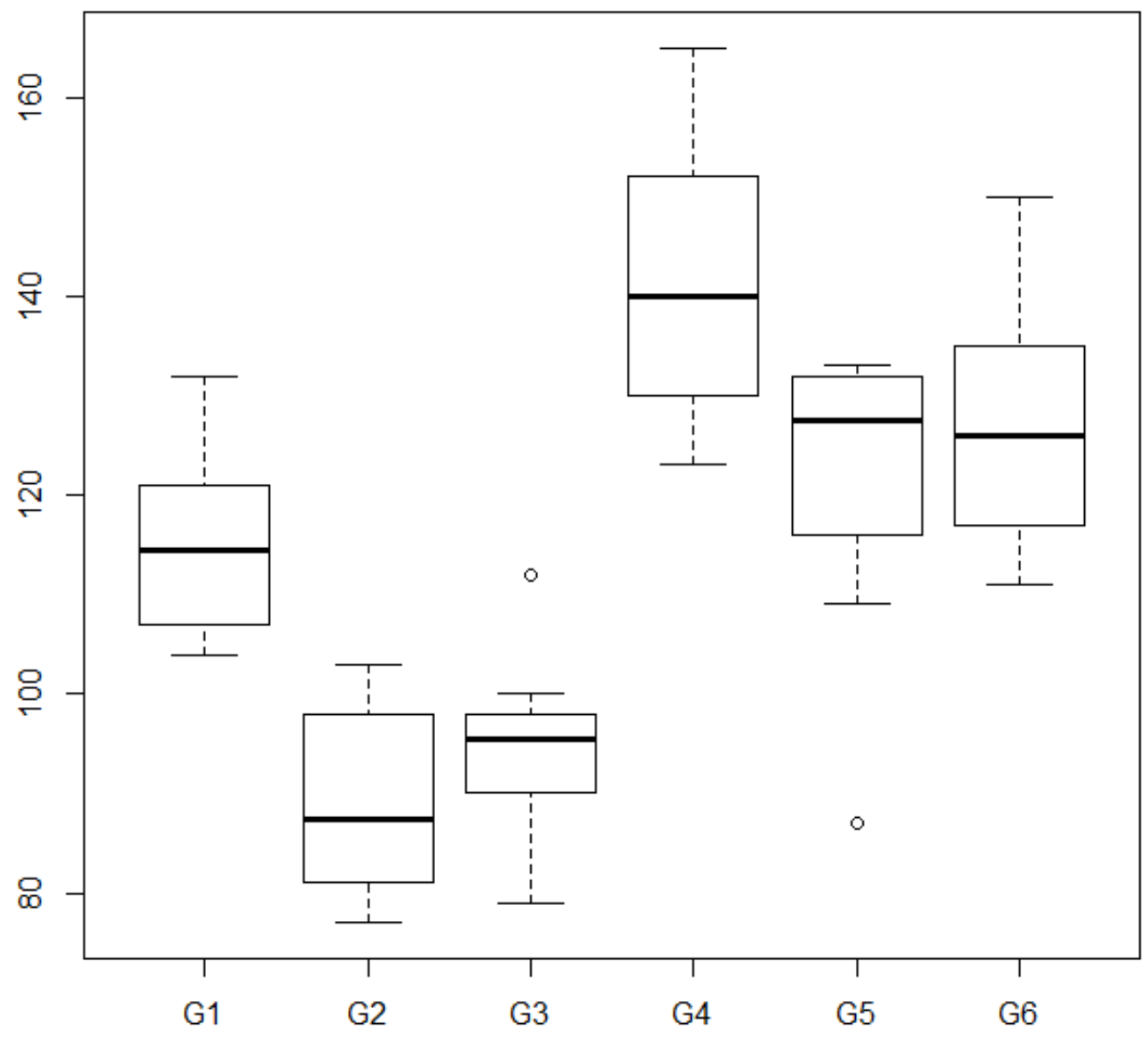

F

Figura 18 - Gráfico em Box-plot da espessura dos infiltrados inflamatórios, ilustrando a mediana (-), valor mínimo e máximo (-), $1^{\circ}$ e $3^{\circ}$ quartil (borda inferior e superior do retângulo). Grupo 1-Sham; Grupo 2- EEAV+; Grupo 3 EEAV-; Grupo 4- Nicotina; Grupo 5 - Nicotina e EEAV +; Grupo 6 - Nicotina e EEAV -. 


\subsection{Valores referentes a área de gap}

Os dados referentes a espessura do GAP (espaço entre o tecido transplantado e o leito receptor) entre os grupos foram avaliados pelo teste ANOVA e post-hoc de

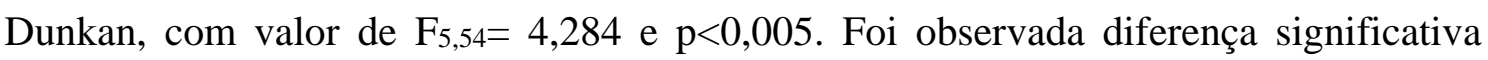
$(\mathrm{p}<0.05)$ entre os grupos 1, 2 e 3 quando comparados com os grupos 4 , 5 e 6 , do grupo 4 quando comparado aos demais grupos, e dos grupos 5 e 6 quando comparados aos grupos 1, 2,3 e 4 . (Tabela 5).

Tabela 5 - Valores médios da área de gap e desvios-padrão do enxerto nos grupos estudados $(\mu \mathrm{m})$.

$$
\text { Média } \pm \text { DP }
$$

\begin{tabular}{lc}
\hline Grupo 1 - Sham & $5,3 \pm 0,7^{\#}$ \\
\hline Grupo 2 - EEAV + & $3,0 \pm 0,93^{\#}$ \\
\hline Grupo 3 - EEAV- & $4,4 \pm 2,17^{\#}$ \\
\hline Grupo 4 - Nicotina & $20,9 \pm 7,88^{£}$ \\
\hline Grupo 5 - Nicotina e EEAV + & $12,6 \pm 5,23^{\beta}$ \\
\hline Grupo 6 - Nicotina e EEAV- & $13,9 \pm 8,06^{\beta}$ \\
\hline
\end{tabular}

DP - Desvio-Padrão

EEAV + - Estimulação elétrica de alta voltagem anódica

EEAV - - Estimulação elétrica de alta voltagem catódica

${ }^{\#} \mathrm{p} \leq 0.05$ vs Grupos 4,5 e 6 .

${ }^{\beta} \mathrm{p} \leq 0.05$ vs Grupos $1,2,3$ e 4

${ }^{£} \mathrm{p} \leq 0.05$ vs Grupos $1,2,3,5$ e 6. 


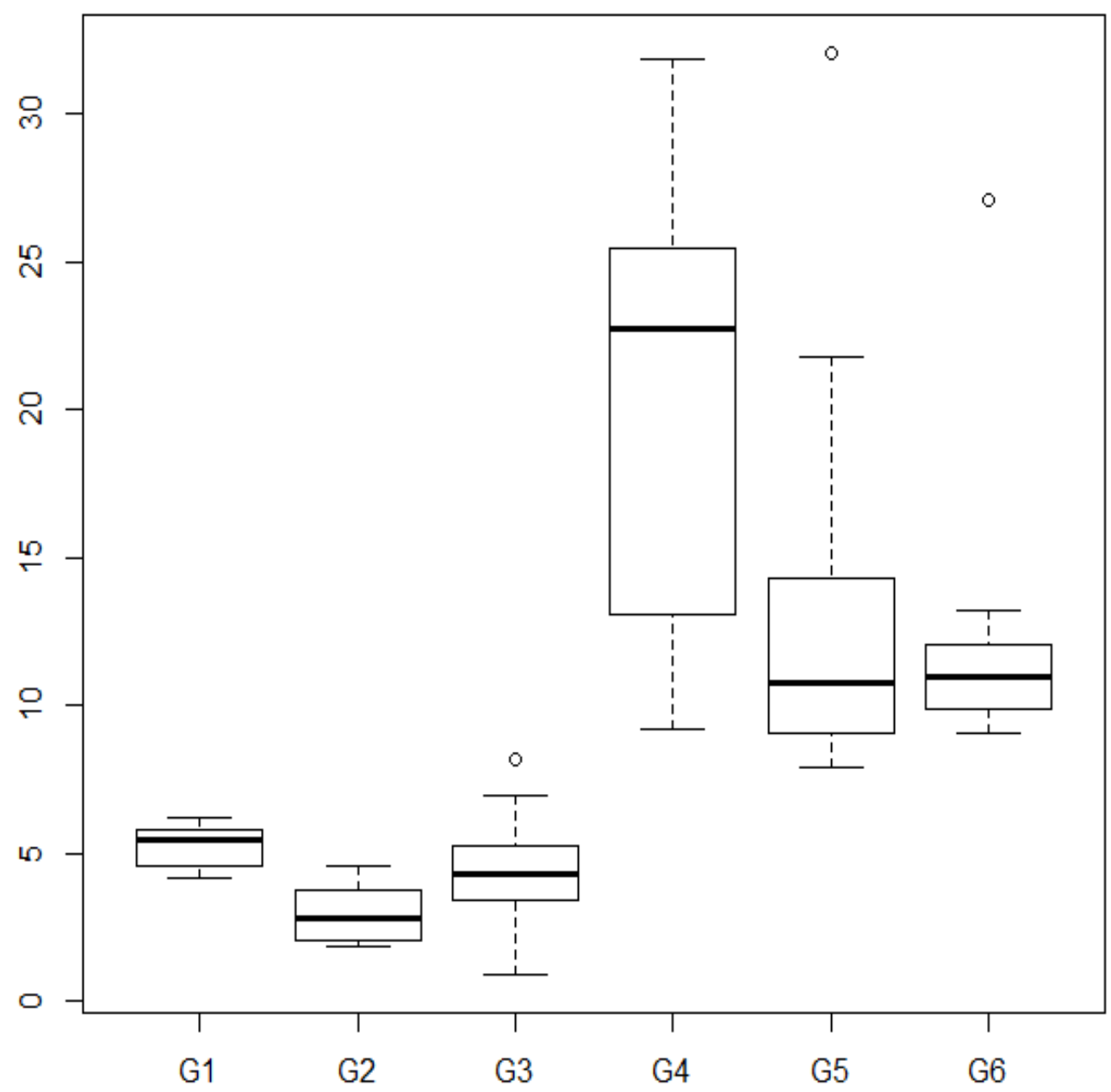

Figura 19 - Gráfico em Box-plot da área de gap, ilustrando a mediana (-), valor mínimo e máximo (-), $1^{\mathrm{o}}$ e $3^{\mathrm{o}}$ quartil (borda inferior e superior do retângulo). Grupo 1-Sham; Grupo 2- EEAV+; Grupo 3 - EEAV-; Grupo 4Nicotina; Grupo 5 - Nicotina e EEAV +; Grupo 6 - Nicotina e EEAV -. 


\subsection{Valores da quantidade de fator de crescimento do endotélio vascular.}

O fator de crescimento do endotélio vascular (Vascular Endothelial Grow Factor - VEGF) entre os grupos foi avaliado pelo teste ANOVA e post-hoc de Dunkan, com valor de $F_{5,54}=4,284$ e $p<0,005$. Foi observada diferença significativa $(p<0.05)$ entre $o$ grupo 4 quando comparado com os demais grupos (Tabela 6).

Tabela 6 - Valores médios e desvios-padrão da quantidade de fator de crescimento do endotélio vascular (VEGF) dos enxertos, nos grupos estudados.

\begin{tabular}{lc}
\hline & Média \pm DP \\
\hline Grupo 1 - Sham & $1,5 \pm 0,40$ \\
\hline Grupo 2 - EEAV + & $2,7 \pm 1,08$ \\
\hline Grupo 3 - EEAV- & $2,3 \pm 1,69$ \\
\hline Grupo 4 - Nicotina & $0,6 \pm 0,25^{\#}$ \\
\hline Grupo 5 - Nicotina e EEAV + & $2,0 \pm 1,29$ \\
\hline Grupo 6 - Nicotina e EEAV- & $1,4 \pm 0,45$ \\
\hline $\begin{array}{l}\text { DP - Desvio-Padrão } \\
\text { EEAV + - Estimulação elétrica de alta voltagem anódica } \\
\text { EEAV - Estimulação elétrica de alta voltagem catódica } \\
\text { \# } \leq 0.05 \text { vs Grupos 1,2, 3, 5 e 6. }\end{array}$
\end{tabular}




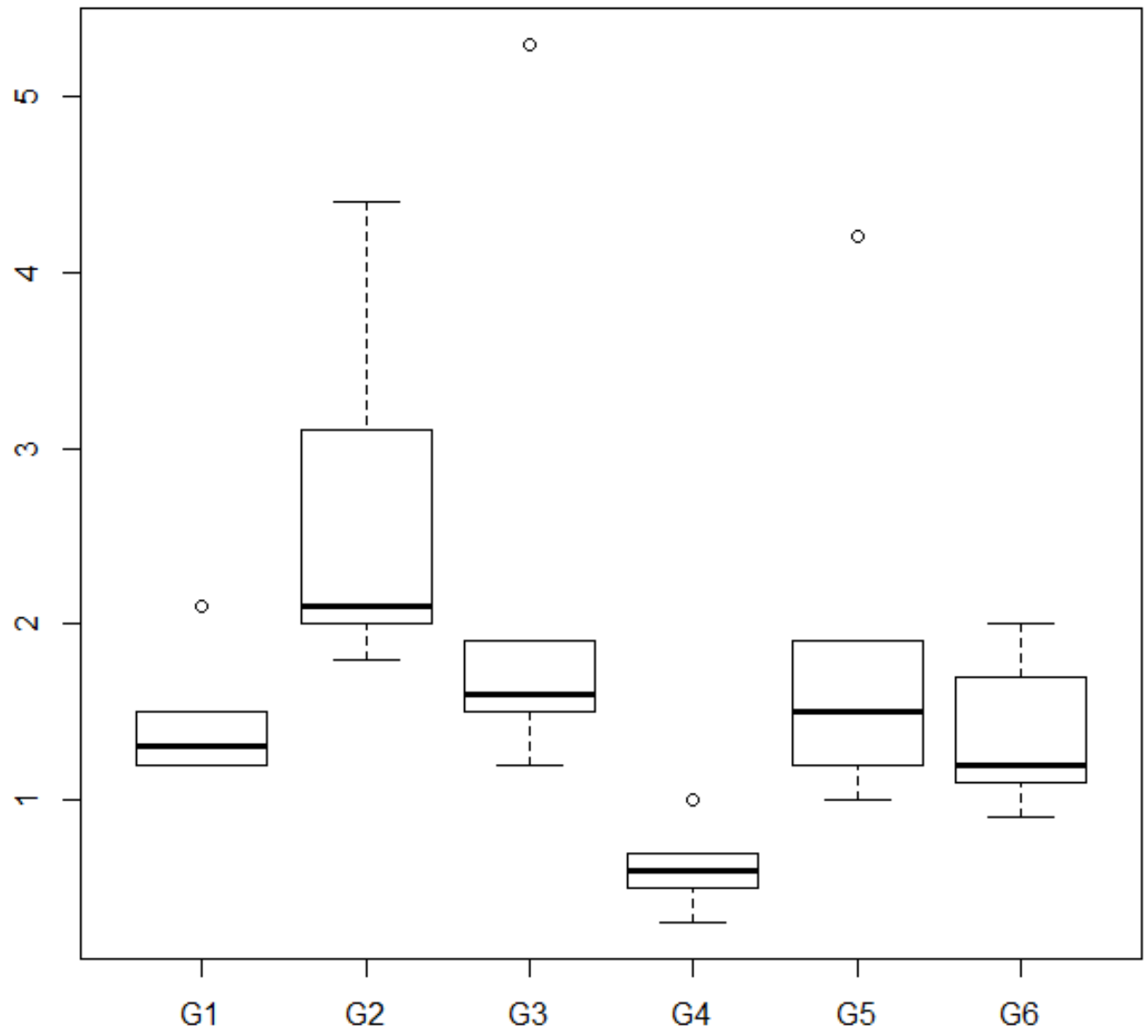

Figura 20 - Gráfico em Box-plot do fator de crescimento do endotélio vascular (VEGF) ilustrando a mediana (-), valor mínimo e máximo $(-), 1^{\circ}$ e $3^{\circ}$ quartil (borda inferior e superior do retângulo). Grupo 1- Sham; Grupo 2EEAV+; Grupo 3 - EEAV-; Grupo 4- Nicotina; Grupo 5 - Nicotina e EEAV +; Grupo 6 - Nicotina e EEAV -. 


\subsection{Valores do Fator VIII.}

Os dados referentes ao fator VIII do enxerto entre os grupos foram avaliados pelo teste ANOVA e post-hoc de Dunkan, com valor de $F_{5,54}=4,284$ e $p<0,005$. Foi observada diferença significativa $(\mathrm{p}<0.05)$ entre os grupos 1 e 2 , quando comparados com os Grupos 3, 4, 5 e 6, do grupo 3 quando comparado aos grupos 2, 4, 5 e 6, do grupo 4 quando comparado aos grupos 1, 2, 3 e 5, do grupo 5 quando comparado aos grupos 1, 2 e 4 dos grupos 5 e 6 quando comparados aos grupos 1, 2,3 e do grupo 6 quando comparado aos grupos 1, 2 e 3. (Tabela 7).

Tabela 7 - Valores médios referentes ao fator VIII e desvios-padrão do enxerto nos grupos estudados $(\mu \mathrm{m})$.

\section{Média \pm DP}

\begin{tabular}{lc}
\hline Grupo 1 - Sham & $4,1 \pm 1,25^{\#}$ \\
\hline Grupo 2 - EEAV + & $5,2 \pm 1,70^{\#}$ \\
\hline Grupo 3 - EEAV- & $3,7 \pm 0,78^{\beta}$ \\
\hline Grupo 4 - Nicotina & $0,6 \pm 0,51^{£}$ \\
\hline Grupo 5 - Nicotina e EEAV + & $2,4 \pm 0,74^{*}$ \\
\hline Grupo 6 - Nicotina e EEAV- & $1,7 \pm 1,32^{\Omega}$ \\
\hline
\end{tabular}

DP - Desvio-Padrão

EEAV + - Estimulação elétrica de alta voltagem anódica

EEAV - - Estimulação elétrica de alta voltagem catódica

${ }^{\#} \mathrm{p} \leq 0.05$ vs Grupos 3, 4, 5 e 6.

$\Omega_{\mathrm{p}} \leq 0.05$ vs Grupos 1,2 e 3

${ }^{\beta} \mathrm{p} \leq 0.05$ vs Grupos $2,4,5$ e 6.

${ }_{\mathrm{p}} \leq 0.05$ vs Grupos $1,2,3$ e 5.

* $\mathrm{p} \leq 0.05$ vs Grupos 1, 2 e 4. 


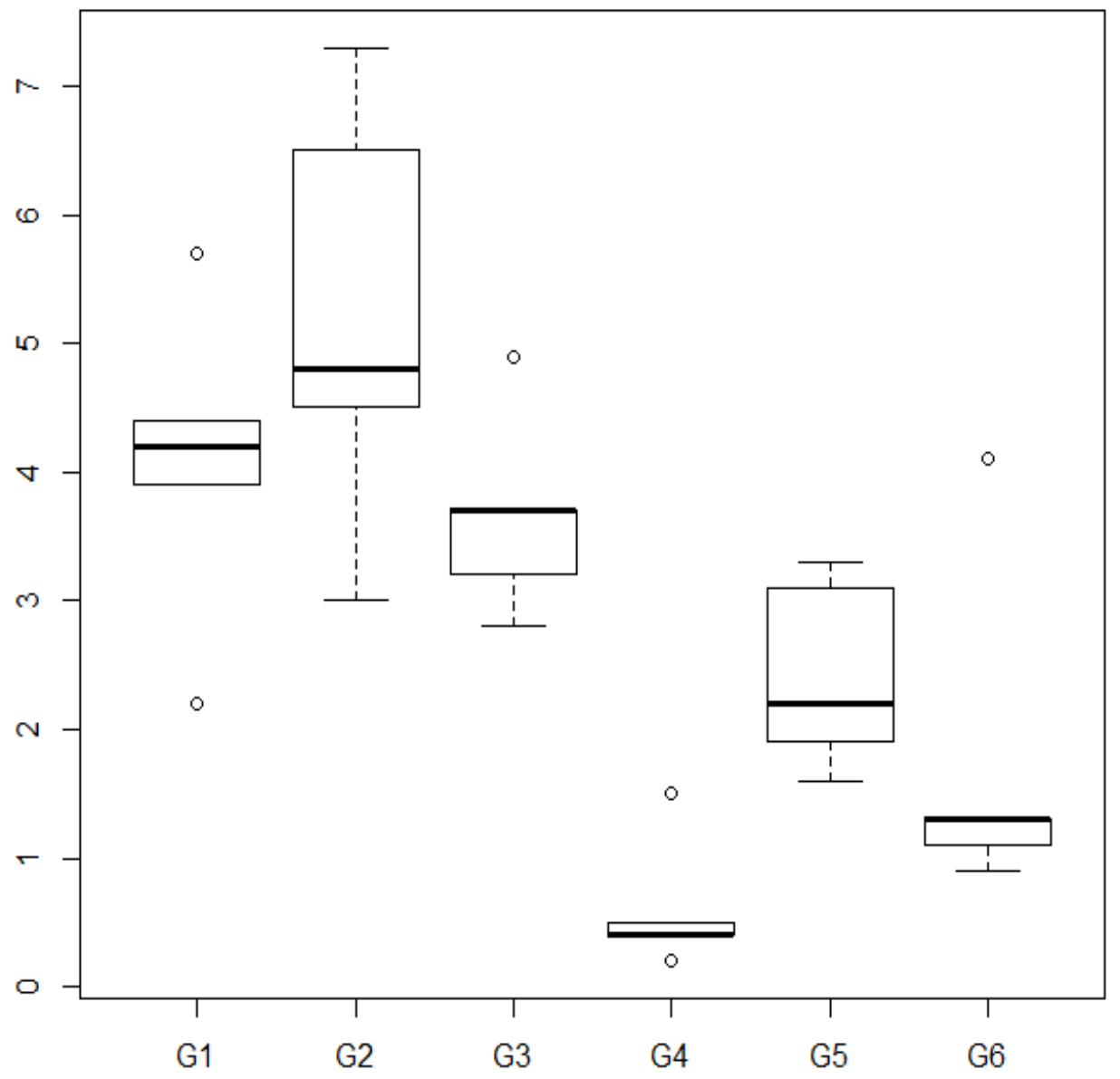

Figura 21 - Gráfico em Box-plot do fator VIII ilustrando a mediana (-), valor mínimo e máximo (-), $1^{\circ}$ e $3^{\circ}$ quartil (borda inferior e superior do retângulo). Grupo 1- Sham; Grupo 2- EEAV+; Grupo 3 - EEAV-; Grupo 4Nicotina; Grupo 5 - Nicotina e EEAV +; Grupo 6 - Nicotina e EEAV -. 
Discussão 


\section{DISCUSSÃO}

O tabagismo é descrito como prejudicial em processos de reparo, promovendo inibição da função da célula endotelial, dos fibroblastos e do crescimento endotelial vascular, comprometendo a circulação periférica e redução da contração da ferida (Michaud et al., 2003; Su, et al., 2004; Midttun, Sejrsen, Paaske, 2006; Sørensen et al., 2010). Sendo assim, é relevante a busca de intervenções terapêuticas que possam minimizar os efeitos deletérios da nicotina nos tecidos, que no presente estudo ocorreu por meio da avaliação dos efeitos da estimulação elétrica de alta voltagem na integração de enxertos de pele total em ratos submetidos à ação da nicotina.

A estimulação elétrica é um recurso muito utilizado no manejo de feridas de difícil reparo e é considerada uma intervenção terapêutica eficiente que reflete na redução do tempo de tratamento, promovendo impacto socioeconômico importante (UdDin, Bayat, 2014; Kloth, 2014; Ashrafi et al., 2017; Hunckler, de Mel, 2017). A intervenção por meio da estimulação elétrica de alta voltagem (EEAV) merece destaque (Weiss, Kirsner, Eaglstein, 1990; Houngton et al., 2003; Silva et al., 2010; Thakral et al., 2013; Kloth, 2014; Ud-Din et al., 2015; Ashrafinet al., 2016; Neves et al., 2016).

A viabilidade de retalhos experimentais afetados pela exposição a nicotina tem sido estudada, demonstrando a influência deletéria da substância (Kaufman et al., 1984; Ely et al., 2009; Selçuk et al., 2012; Das Neves et al., 2011; Neves et al., 2011; Shah et al., 2012; Neves et al., 2016.). No presente estudo foi observado que o grupo que foi submetido a nicotina e não recebeu nenhuma estimulação, apresentou a maior porcentagem de contração do enxerto, fato que pode indicar a provável influência negativa da nicotina na sua integração, por promover isquemia, e por consequência diminuição do fluxo sanguíneo no local (Silverstein, 1992).

Dentre as complicações esperadas relacionadas aos enxertos cutâneos, a falta de integração ao leito receptor é destaque, seguida da temida contração excessiva (Lofêgo Filho et al., 2006). Enxertos de pele humana de espessura total contraem minimamente, e na presença de infecção, a contração é de quase metade da área inicial, e, em sua ausência, enxerto/leito receptor contraem-se em um terço da área inicial; e enxerto de 
espessura parcial podem levar a necrose e fibrose da pele (Stephenson, Griffiths, La Hausse-Brown, 2000; Chen et al, 2017).

No presente estudo, a porcentagem de contração tecidual dos enxertos foi maior no grupo de animais que foram expostos a nicotina e não receberam estimulação (grupo 4), com porcentagem média de contração de 16,6\%, semelhante ao resultado encontrado por Berezovsky et al. (2015) que observaram 12,04\% de contração do enxerto de espessura total. É provável que os achados tenham sido encontrados pelo fato que enxertos de pele autólogos são frágeis e podem contrair-se significativamente durante o processo de cicatrização, ainda mais quando a mesma se encontra alterada devido ao uso da substância que pode causar insuficiência do suprimento sanguíneo, tendo por consequência degeneração e também necrose (Zografou, Papadopoulos, 2003).

A aplicação de estimulação elétrica pode interferir na viabilidade de tecidos, provavelmente relacionados pela questão circulatória (Eroglu et al., 1997, Neves et al., 2016). Respostas circulatórias podem ser avaliadas por termografia infravermelha, que tem sido amplamente utilizada como método de avaliação simples e não invasivo para acompanhamento e monitorização de disfunções relacionadas (Jiménez et al., 2013; Prindeze et al., 2016; Batinjan et al., 2014; Gurjarpadhye et al., 2015). É provável que a redução da temperatura observada no período pós-operatório, em todos os grupos, pode estar associada a dois fatores característicos da cirurgia de enxertia cutânea. O primeiro seria a transudação do plasma da área receptora, que é absorvido pelo enxerto, com intuito de formar uma malha de fibrina com função de nutrição e fixação (Maeda et al, 1999; Foster et al. 2008). A segunda variável que pode ter interferido é a vasoconstricção induzida pelo anestésico aplicado (Gargiulio et al., 2013).

A influência da ação da EEAV na temperatura cutânea de retalhos miocutâneos ao longo dos dias foi observada (Houghton et al. 2003; Goldman et al., 2004). O comportamento da temperatura no período avaliado no presente estudo demonstrou alteração significativa, sendo que no décimo dia após o procedimento cirúrgico, a temperatura média dos animais assemelha-se ao período pré-cirúrgico, fato que pode estar relacionado à resolução do processo inflamatório.

A partir do período pós-operatório, o grupo submetido à EEAV anódica demonstrou diferença significativa em todos os dias avaliados. Pode-se também inferir, que a menor temperatura encontrada no mesmo grupo, possa ter ocorrido pelo fato do recurso acelerar o processo inflamatório, favorecendo a cicatrização (Brown et al., 
1988; Ahmad, 2008), de forma a evoluir para os estágios de remodelação (Sebastian et al., 2011).

Os efeitos inerentes as diferentes polaridades foram investigadas por estudo (Talebi et al., 2008), que observou que a polaridade positiva foi mais eficiente na redução da área de feridas na pele. Estudos pré-clínicos demonstraram que atividades celulares, como colágenas, síntese de DNA, concentração de ATP e geração de fatores quimiotáxicos, são reforçadas pela estimulação elétrica (Kloth, 2009). Esta também demonstrou aumentar a perfusão tecidual, diminuir o edema, promover a angiogênese e galvanotaxia, direcionando a migração celular no tecido ferido para promover a cicatrização (Nishimura et al., 1996; Sheehan et al., 2003).

Na comparação entre os grupos, foi observado que no décimo dia o grupo 2, que foram os animais estimulados com a polaridade positiva, sem a interferência da droga, apresentaram uma maior temperatura em relação a todos os outros grupos, provavelmente pelo incremento da atividade celular, mais evidente na polaridade positiva, além da simulação de correntes bioelétricas naturais (Nuccitelli, 2003; Huttenlocher, 2007). Foi observado que a exposição prolongada à estimulação elétrica induz a migração direcional de fibroblastos para o ânodo por meio da sinalização de PI3 quinase (Guo et al., 2010). PI3 quinase é caracterizada sendo uma molécula que regula a migração dos fibroblastos para o polo positivo. (Nuccitelli, Erickson, 1983 ; Soong et al., 1990; Brown, Loew, 1994; Bai et al., 2004; Finkelstein et al., 2004; Chao et al., 2007; Forrester et al., 2007). Além disso, demonstrou-se que, a estimulação elétrica induz a migração de queratinócitos, que contribuem para a primeira linha de defesa da pele contra patógenos, e são considerados elementos essenciais na cicatrização (Hampton; King, 2005). A matriz extracelular, os fatores de crescimento, as citocinas e outras moléculas nas feridas possuem efeitos quimiocinéticos e quimiotáticos importantes na cicatrização (Diegelmann, Evans, 2004; Falanga, 2005; Gurtner et al., 2008).

A espessura da epiderme pode sofrer modificações em indivíduos que fazem uso do cigarro, interferindo na migração de queratinócitos (Zia et al., 2000). Outro estudo (Talebi et al., 2007) avaliou a aplicação da corrente direta em feridas em cobaias por 3 semanas, dividindo em um grupo com estimulação catódica e outro anódica, sendo observado efeitos significativos com as duas polaridades, efeitos também apontados em outros estudos (Houghton et al., 2003, Davini et al., 2005). Apesar dos grupos que 
receberam estimulação e também foram expostos a nicotina (grupo 5 e grupo 6) terem apresentado melhores resultados em comparação com o grupo Sham, não foi encontrado diferença significativa neste parâmetro avaliado, provavelmente pelo tempo de estimulação.

No presente estudo foi encontrada maior taxa de infiltrado inflamatório no grupo submetido exclusivamente a ação da nicotina (grupo 4), pela provável influência deletéria da substância. Com a presença de infiltrado inflamatório no enxerto, independentemente da sua localização, relaciona-se com a redução da sobrevida do mesmo (Mengel et al., 2007; Mengel et al., 2009). A resposta quanto a esta variável foi maior nos grupos estimulados e sob a ação da nicotina (grupo 5 e grupo 6), em relação aos grupos que foram apenas estimulados (grupo 1 e grupo 2), e também quando comparada somente ao grupo que recebeu a droga (grupo 4). É provável que este fato seja decorrente da nicotina, por promover vasoconstricção periférica, diminuindo o fluxo sanguíneo que nutre a pele, resultando em isquemia, e por consequência dificultando o reparo tecidual (Silverstein, 1992). Além disso, a estimulação elétrica pode acelerar a resolução do processo inflamatório, avançando para os estágios de remodelação (Vodovnik, Karba, 1992; Sebastian et al., 2011).

Foi observado que o grupo 2, que foi o grupo de animais estimulados com a EEAV com a polaridade positiva, apresentou uma menor taxa de infiltrados inflamatórios quando comparado aos grupos sham, 4, 5 e 6 . Uma hipótese seria pela cascata de eventos durante e após o processo inflamatório/proliferativo da cicatrização (Weiss, Kirsner, Eagistein, 1990; Gentzkow, Miller, 1991; Hampton, King, 2005).

Estudos in vitro e in vivo relataram que a aplicação da polaridade positiva tem alguns efeitos importantes, incluindo a destruição de microrganismos (Kincaid, Lavoie, 1989), aumento, migração e proliferação das células epiteliais (Kloth, McCulloch, 1996), maior atração de macrófagos (Orida, Feldman, 1982), e melhor assimilação de correntes endógenas na ferida (Karba et al., 1997).

A cicatrização de feridas em enxertos de pele se inicia com o processo de embebição, este período é caracterizado por isquemia que perdura nas primeiras 24 até 48 horas em que o enxerto se torna edematoso e é sustentado pelos exsudatos de plasma do leito da ferida. O próximo estágio é a inoculação, no qual um processo de revascularização começa a partir de 48 a 72 horas e dura de 7 a 10 dias. O estágio final é o chamado de neovascularização, e o mesmo ocorre através da angiogênese entre o 
enxerto e o local receptor. No pós-operatório, a nicotina diminui a tensão do oxigênio e prejudica a epitelização da ferida, levando a uma possível deiscência (Benowitz, Lake, Keller, 1987; Jensen et al., 1991; Krueger, Rohrich, 2001).

Adota-se como critério histológico de integração a presença de vasos sanguíneos dos fragmentos enxertados, sendo que enxertos de pele até o quinto dia, apresentam vasos com ausência de fluxo sanguíneo. Os enxertos seriam nutridos nesse período por embebição, podendo evoluir para necrose ou para a efetiva integração. Após o sexto dia até 28 dias posteriormente ao transplante, há a presença de uma circulação dinâmica em vasos com o mesmo padrão morfológico aos originais. Portanto, após o sexto dia, a presença no tecido enxertado de vasos sanguíneos de aspecto normal e contendo hemácias, viabiliza o critério vascular (Haller, Billingham 1967; Seyhan, 2011; Chua et al., 2016). Ter um suprimento sanguíneo suficiente é um fator primordial para qualidade do enxerto (Seyhan, 2011). Os vasos sanguíneos recém-formados no leito da ferida fornecem substrato energético de nutrientes e oxigênio, melhorando a função do tecido (Chua et al., 2016).

A taxa de integração do enxerto no presente estudo foi observada por meio da avaliação da espessura do gap (espaço entre o tecido transplantado e o leito receptor). $\mathrm{O}$ grupo submetido a ação da nicotina isolada (grupo 4), obteve maior área, ou seja, a menor taxa de integração do enxerto, provável consequência da ação da substância nos tecidos envolvidos (Silverstein, 1992; Wahie, Lawrence, 2007, Gill et al., 2013). Os grupos 5 e 6 , que foram os grupos estimulados com polaridade positiva e negativa respectivamente, e submetidos previamente pela nicotina apresentaram valores menores quando comparados com o grupo 4. Estes resultados podem sugerir que apesar da presença da nicotina, o uso do recurso terapêutico pode ter minimizado a formação de lacunas na integração do tecido. Os grupos 1 e 2 que foram os grupos que não receberam a interferência da nicotina, e foram somente estimulados com a alta voltagem, com a polaridade positiva e negativa respectivamente, apresentaram valores menores da área de gap quando comparado aos grupos 4, 5 e 6. Isso pode inferir quão prejudiciais são os efeitos da droga no quesito integração tecidual, e sugerir também que isso possa ter ocorrido pelo fato do recurso influenciar a viabilidade e reparo dos enxertos de pele.

Dentre as características citadas na literatura no que se diz respeito a integração dos enxertos autólogos são: aderência, perfusão e viabilidade do segmento de pele 
transferido, este depende obrigatoriamente de sua vascularização (Franco, Cláudio-daSilva, 2002). Nas primeiras 24 horas após a enxertia, o plasma que transuda a área receptora é absorvido pelo enxerto formando uma malha de fibrina que serve para sua fixação e nutrição (fase de embebição plasmática). Na sequência, pequenos capilares se anastomosam comunicando a superfície do enxerto a superfície do leito receptor, que é a chamada de fase inoculatória. O enxerto encontra-se ainda fragilmente fixado, podendo estar cianótico. O surgimento e proliferação de novos vasos é que irá garantir a sobrevivência da pele transplantada. A partir disso, a circulação sanguínea é restabelecida no período referente ao quinto até sétimo dia após a intervenção cirúrgica, que já se caracteriza a fase de revascularização (Franco, Cláudio-da-Silva, 2002; Golcman, Golcman, 2002).

O fator de crescimento do endotélio vascular, do inglês Vascular Endothelial Growth Factor (VEGF), está relacionado a angiogênese, e tem papel importante no processo de reparo tecidual (Zhang et al., 2001) e na sobrevida de retalhos (Lineaweaver et al., 2004). A estimulação elétrica tem a capacidade de aumentar a expressão de VEGF em feridas (Zhao et al., 2004; Baia et al., 2011; Mohajeri-Tehrani et al., 2014; Ud-Din et al., 2014).

No presente estudo pode-se observar maior quantidade de VEGF entre os grupos 2 e 3, que foram os grupos que não receberam a influência da nicotina e foram submetidos a EEAV, quando comparados com o grupo 4, submetido a ação da nicotina sem estimulação, que apresentou a menor quantidade de VEGF. É provável que a influência do recurso terapêutico aplicado esteja relacionada a resposta encontrada. A angiogênese pode estar associada com os efeitos da corrente elétrica no tecido endotelial, que demonstrou induzir uma maior liberação de mediadores químicos que estimulam a proliferação celular (Barbic, Chen, Lau, 1999).

Em um local onde há uma lesão, ou dano tecidual, é geralmente caracterizado como sendo uma camada eletropositiva em comparação com a pele intacta circundante (Jaffe, Vanable, 1984; Vodovnik, Karba, 1992; Gentzkow, 1993; Ojingwa, Isseroff, 2003; Talebi et al., 2008). A pele humana não danificada possui um potencial elétrico endógeno e um potencial de corrente transcutânea de 10-60 Mv (Foulds, Barker, 1983), mais especificamente, o epitélio da camada córnea, ativa os íons para manter uma diferença de potencial elétrico transepitelial - DP (Klyce, 1972). Este é gerado pelo movimento de íons de sódio através de bombas de $\mathrm{Na}^{+} / \mathrm{K}^{+}$ATPase na epiderme 
(McGinnis, Vanable, 1986). Assim, quando a pele está ferida, uma corrente de lesão é gerada como resultado da súbita mudança de potencial elétrico nos tecidos adjacentes à margem da ferida (Borgens, 1988; Besne et al., 2002).

A estimulação elétrica, independentemente do regime de polaridade, beneficia a cicatrização de feridas, entretanto, a sua associação parece ser satisfatória, como observado com a estimulação com a polaridade positiva nos primeiros três dias da lesão e a estimulação com polaridade negativa no restante dos dias, podendo levar a um tecido reparado mais forte (Mehmandoust et al., 2007).

A fase inflamatória tem início imediatamente após a lesão, com vasodilatação e aumento da permeabilidade vascular promovendo a quimiotaxia. No presente estudo, a quantificação de vasos sanguíneos foi efetuada por meio da técnica de imunohistoquímica, utilizando-se anticorpo antifator VIII, também denominado fator de Von Willebrand. O Fator VIII (FVIII) é uma proteína de coagulação de sangue essencial, uma componente chave do sistema de coagulação de sangue da fase fluida (Mazurkiewicz-Pisarek et al., 2015), sendo altamente específico para tecido vascular e foi utilizado como marcador de vascularização em alguns estudos (Jerdan, Michels e Glaser, 1991; Skinovsky, 2005). No presente estudo foi observado que a maior taxa de Fator VIII foi do grupo 2, estimulado com a polaridade positiva, e a menor taxa de fator VIII foi do grupo 4, que foi o grupo somente exposto a nicotina, sem estimulação. Talvez isso possa ter ocorrido pelo déficit circulatório produzido pela droga. Em outra análise, pelo fato da polaridade positiva poder interferir na circulação local e influenciar na vascularização do tecido com o crescimento de novos capilares (Nelson, Hayes, Currier, 2003; Daeschlein et al., 2007). Os grupos que foram submetidos somente a EEAV, sem a interferência da nicotina (grupos 2 e 3) quando comparados aos que foram submetidos a EEAV com a interferência da nicotina (grupos 4 e 5) pode-se observar que a taxa de Fator VIII nos grupos com a ausência da nicotina é maior.

Este estudo abre uma ampla gama de possibilidades para o uso da EEAV na prática clínica, porém, ainda assim, necessita ser mais explorado, para a modulação da corrente no intuito de aumentar a integridade de enxertos de pele em tecidos que possuem a presença da nicotina. Estudos adicionais se fazem necessários para aperfeiçoar a utilização do recurso terapêutico com outros parâmetros. 
Conclusão 


\section{CONCLUSÃO}

Diante dos achados deste estudo, pode-se concluir que a estimulação elétrica de alta voltagem pode influenciar positivamente na integração do enxerto de pele em ratos submetidos à nicotina.

A estimulação elétrica de alta voltagem com polaridade positiva promoveu maior integração de enxertos de pele total em ratos submetidos à ação da nicotina. 
Referências 


\section{REFERÊNCIAS}

Ahmad, E.T. High-voltage pulsed galvanic stimulation: Effect of treatment duration on healing of chronic pressure ulcers. Mediterr. Counc. Burn. Fire Disasters 2008, 21, 124128.Aköz T, Akan M,YildirimS. If you continue to smoke, we may have a problem: smoking's effects on plastic surgery. Aesthetic Plast Surg.2002; 26(6):477-82.

Amâncio ACG, Barbieri CH, Mazzer N, Garcia SB, Thomazini JA. Estimulação ultrassônica da integração de enxertos de pele total: Estudo experimental em coelhos. Acta Ortop Brasil. 2006; 14(5): 276-279.

Ashrafi M, Alonso-Rasgado T, Baguneid M, Bayat A. The efficacy of electrical stimulation in experimentally induced cutaneous wounds in animals. Vet Dermatol. 2016; 27(4):235-57.

Ashrafi M, Alonso-Rasgado T, Baguneid M, Bayat A. The efficacy of electrical stimulation in lower extremity cutaneous wound healing: A systematic review. Exp Dermatol 2017; 26 (2):171-178.

Baia H, Forrestera JV, Zhaoa M. DC electric stimulation upregulates angiogenic factors in endothelial cells through activation of VEGF receptors. Cytokine. 2011; 55(1): 110115 .

Batinjan G, Zore Z, Celebic A, Papic M, Panduric DG, Zore IF. Thermographic monitoring of wound healing and oral health-related quality of life in patients treated with laser (aPDT) after impacted mandibular third molar removal. Int. J. Oral Maxillofac. Surg. 2014; 43: 1503-1508.

Barbic AM, Chen CC, Lau LF. Fisp12/mouse connective tissue growth factor mediates endothelial cell adhesion and migration throughintegrin alphavbeta3, promotesendothelial cell survival, and induces angiogenesis in vivo. Mol Cell Biol 1999, 19:2958.

Bai H, McCaig CD, Forrester JV, et al. DC electric fields induce distinct preangiogenic responses in microvascular and macrovascular cells. Arterioscler Thromb Vasc Biol. 2004; (2) 4: 1234-1239.

Benowitz NL, Lake T, Keller KH, Lee BL. Prolonged absorption with development of tolerance to toxic effects after cutaneous exposure to nicotine. Clin Pharmacol Ther. 1987; 42 (1): 119-20. 
Besne' I, Descombes C, Breton I. Effect of age and anatomical site on density of sensory innervation in human epidermis. Arch Dermatol 2002;138:1445.

Berezovsky A B, Pagkalos A V, Silberstein E, Shoham Y, Rosenberg L, Krieger Y. Primary contraction of skin grafts: a porcine preliminary study. Plast Aesthet Res. 2015; 2(1).

Biondo-Simões MLP, Tetilla MR, Biondo-Simões R, Martin MM, Repka JCD, Zanato D. The influence of nicotine on the density of collagen in cutaneous scars in rats. Rev Col Bras Cir. 2009; 36(5): 425-430.

Borgens RB. Voltage gradients and ionic currents in injured and regenerating axons. Adv Neurol 1988; 47:51.

Brown M, McDonnell MK, and Menton DN: Electrical stimulation effects on cutaneous wound healing in rabbits. A follow-up study. Phys Ther. 1988; 68: 955.

Brown MJ, Loew LM. Electric field-directed fibroblast locomotion involves cell surface molecular reorganization and is calcium independent. J Cell Biol. 1994;127:117-128.

Castana O, Dimitrouli A, Argyrakos T, Theodorakopoulou E, Stampolidis N, Papadopoulos E, Pallantzas A, Stasinopoulos I, Poulas K.Wireless electrical stimulation: an innovative powerful tool for the treatment of a complicated chronic ulcer. Int J Low Extrem Wounds. 2013;12 (1):18-21.

Chao PH, Lu HH, Hung CT, et al. Effects of applied DC electric field on ligament fibroblast migration and wound healing. Connect Tissue Res. 2007; 48: 188-197.

Chen L, Xing Q, Zhai Q, Tahtinen M, Zhou F, Chen L, Xu Y, Qi S, Zhao F.Prevascularization Enhances Therapeutic Effects of Human Mesenchymal Stem Cell Sheets in Full Thickness Skin Wound Repair.Theranostics. 2017;7 (1):117-131.

Chua AWC, Khoo YC, Tan BK, Tan KC, Foo CL, Chong SJ. Skin tissue engineering advances in severe burns: review and therapeutic applications. Burns \& Trauma. 2016; 19 (4): 3.

Cramp AF L, Gilsenan C, Lowe AS and Walsh DM. The effect of high- and lowfrequency transcutaneouselectrical nerve stimulation upon cutaneous blood flow and skin temperature in healthy subjects. Clin Physiol. 1999; 20 (2): 150-157. 
Daeschlein G, Assadian O, Kloth LC, Meinl C, Ney F, Kramer A. Antibacterial activity of positive and negative polarity low-voltage pulsed current (LVPC) on six typical Gram-positive and Gram-negative bacterial pathogens of chronic wounds. Wound Repair Regen. 2007; 15 (3): 399-403.

Das Neves LM, Marcolino AM, Prado RP, Ribeiro Tde S, Pinfildi CE, Thomazini JA. Low-level laser therapy on the viability of skin flap in rats subjected to deleterious effect of nicotine. Photomed Laser Surg. 2011; 29 (8): 581-7.

Davini R, Nunes CV, Guirro ECO, Guirro RRJ. Estimulação elétrica de alta voltagem: uma opção de tratamento. BJPT. 2005: 9(3): 249-256.

Diegelmann RF, Evans MC. Wound healing: an overview of acute, fibrotic and delayed healing. Front Biosci. 2004;9:283-289.

Dinos ME, Borke JL, SWIEC GD , McPherson JC, Goodin JL, Chuang AH.In vitro study of the adverse effect of nicotine and physical strain on human gingival fibroblasts as a model of the healing of wounds commonly found in the military. Mil Med. 2015; 180(3): 86-91.

Ely PB, Kobayashi LA, Campos JHO, Gomes HC, Juliano Y, Ferreira LM. Nicotina em retalho TRAM em ratos. Acta Cir Bras. 2009; 24(3): 216-20.

Ely PB, Ferreira LM. Transverse rectus abdominis musculocutaneuous flap (TRAM flap) - experimental model in rats. Acta Cir Bras. 2003; 18:46-1853.

Eroglu E, Unal E, Oksuz O. The effect of electrical dermal stimulation on ischemic skin flap necrosis in guinea pigs. Gazi Medi J. 1997; 8: 97-100.

Falanga V. Wound healing and its impairment in the diabetic foot. Lancet. 2005; $366: 1736$.

Finkelstein E, Chang W, Chao PH, et al. Roles of microtubules, cell polarity and adhesion in electric-field-mediated motility of 3 T3 fibroblasts. J Cell Sci. 2004; (117) $1533-1545$.

Foster K, Greenhalgh D, Gamelli RL, Mozingo D, Gibran N, Neumeister M, Abrams SZ, Hantak Eet al. Efficacy and safety of a fibrin sealant for adherence of autologous skin grafts to burn wounds: results of a phase 3 clinical study. J Burn Care Res. 2008, 29(2):293-303. 
Foulds IS, Barker AT. Human skin battery potentials and their possible role in wound healing. Br J Dermatol. 1983; 109(5):515-22.

Forrester JV, Lois N, Zhao M, et al. The spark of life: the role of electric fields in regulating cell behaviour using the eye as a model system. Ophthalmic Res. 2007; 39:416.

Fujino T, Kiyoizumi T, Kubota J, Oshiro T. Clinical effect of diode laser to improve fair take of the grafted skin. Keio J Med. 1986; 35(1): 28-35.

Francis A, Baynosa RC.Hyperbaric Oxygen Therapy for the Compromised Graft or Flap. Adv Wound Care. 2017; 6(1):23-32.

Franco D, Cláudio-da-Silva CS. Enxertos, retalhos e implantes. In: Franco T. Princípios de cirurgia plástica. São Paulo: Ateneu; 2002; (87): 106.

Franek A, Kostur R, Polak A, Taradaj J, Szlachta Z, Blaszczak E, Dolibog P, Dolibog P, Koczy B, Kucio C.Ostomy Wound Manage. 2012;58 (3):30-44.

GargiuloS, Gramanzini, Liuzzi R, Greco A et al. Effects of some anesthetic agents on skin microcirculation evaluated by laser Doppler perfusion imaging in mice. Veter Res 2013, (9): 255.

Gentzkow GD, Miller KH. Electrical stimulation for dermal wound healing. Clin Podiatr Med Surg. 1991;8 (4):827-41.

Gentzkow GD: Electrical stimulation to heal dermal wounds. J Dermatol Surg Oncol. 1993,753 .

Golcman B, Golcman R. Principais tipos e indicações de enxertos. In: Gadelha AR, Costa IM, editores. Cirurgia dermatológica em consultório. São Paulo: Atheneu; 2002; 285-91.

Goldman RJ, Brewley BL, Golden MA. Electrotherapy reoxygenates inframalleolar ischemic wounds on diabetic patients: a case series. Adv Skin Wound Care. 2002; 15(3): 112-120. 
Goldman R, Rosen M, Brewley B, Golden M. Electrotherapy promotes healing and microcirculation of infrapopliteal ischemic wounds: a prospective pilot study. Adv Skin Wound Care. 2004; 17(6): 284-294.

Gomes HC, Campos JHO, Ferreira LM, Kobayashi LA. Experimental model to study the effect of nicotine in a random skin flap, in the rat. Acta Cir Bras. 2004; 1-4.

Gonçalves AC, Barbieri CH, Mazzer N, Garcia SB, Thomazini JA. Can therapeutic ultrasound influence the integration of skin grafts? Ultrasound Med Biol. 2007; 33(9): 1406-1412.

Gill JF, Yu SS, Neuhaus IM. Tobacco smoking and dermatologic surgery. J Am Acad Dermatol. 2013; 68(1):167-72.

Guo, A.; Song, B.; Reid, B.; Gu, Y.; Forrester, J.V.; Jahoda, C.A.; Zhao, M. Effects of physiological electric fields on migration of human dermal fibroblasts. J. Investig. Dermatol. 2010, 130, 2320-2327.

Gurjarpadhye AA, Parekh MB, Dubnika A, Rajadas J, Inayathullah M. Infrared Imaging Tools for Diagnostic Applications in Dermatology. SMJCM. 2015; 1 (1): 1-5.

Gurtner GC, Werner S, Barrandon Y, et al. Wound repair and regeneration. Nature. 2008; 453:314-321.

Haller JA, Billingham RE. Studies of the origin of the vasculature in free skin grafts. Ann Surg. 1967; 166(6):896-01.

Hampton S, King L. Healing an intractable wound using bio-electrical stimulation therapy. Br J Nurs. 2005;14 (15):30-32.

Hunckler J,de Mel A. A current affair: electrotherapy in wound healing. J Multidiscip Healthc. 2017; 179-194.

Huttenlocher A. and Horwitz AR: healing of wounds with electrical potential. N Engl J Med 2007; 356: 303.

Jerdan, J. A.; Michels, R. G.; Glaser, B. M. Extracellular matrix of newly forming vessels - an immunohistochemical study. Microvasc. Res., New York. 1991; 42:255265. 
Jorgensen LN, Kallehave F, Christensen E, Siana JE, Gottrup F. Less collagen production in smokers. Surgery. 1998; 123(4): 450-455.

Hampton, S.; King, L. Healing an intractable wound using bio-electric stimulation therapy. Br. J. Nurs. 2005, 14, 30-32.

Houghton PE, Kincaid CB, Lovell M, Campbell KE, Keast DH, Woodbury MG, Harris KA. Effect of electrical stimulation on chronic leg ulcer size and appearance. Phy Ther. 2003; 83: 17-28.

Jaffe LF, Vanable JW, Jr. Electric fields and wound healing. Clin Dermatol. 1984; 2:34.

Jensen JA, Goodson WH, Hopf HW, Hunt TK. Cigarette smoking decreases tissue oxygen. Arch Surg. 1991;126 (9):1131-4.

Jiménez MAM, García JA, Rodríguez RV, Medlich MAM, Dietsch LJP, Gaona FIG, Machuca ESK, González FJ, Aguilar JMS. Local Use of Insulin in Wounds of Diabetic Patients: Higher Temperature, Fibrosis, and Angiogenesis. Plastic and Reconstructive Surgery. 2013; 132: 1015.

Karba R, Semrov D, Vodovnik L, Benko H, Savrin R. DC electrical stimulation for chronic wound healing enhancement. Part 1. Clinical study and determination of electrical field distribution in the numerical wound model. Bioelectrochem Bioenerg. 1997;43 (2):256-70.

Kaufman T, Eichenlaub EH, Levin M, Hurwitz DJ, Klain M. Tobacco smoking impairment of experimental flap survival. Ann Plast Surg. 1984; 13(6):468-72.

Kim TH, Cho HY, Lee SM. High-voltage pulsed current stimulation enhances wound healing in diabetic rats by restoring the expression of collagen, $\alpha$-smooth muscle actin, and TGF- $\beta 1$ Tohoku J Exp Med. 2014; 234(1):1-6.

Kincaid CB, Lavoie KH. Inhibition of bacterial growth in vitro following stimulation with high voltage, monophasic, pulsed current. Phys Ther. 1989; 69(8):651-55. 
Kloth L and Zhao M: Endogenous and exogenous electrical fields for wound healing. In: Wound Healing: Evidence-Based Management, 4th Edition, edited by McCulloch J and Kloth L, eds. Brick, NJ: F.A. Davis, 2009; 450-513.

Kloth LC. Electrical Stimulation Technologies for Wound Healing. Adv Wound Care 2014;3 (2):81-90.

Kloth LC, McCulloch JM. Promotion of wound healing with electrical stimulation. Adv Wound Care. 1996; 9(5): 42-45.

Klyce SD. Electrical profiles in the corneal epithelium. J Physiol. 1972; 226:407-429.

Krueger JK, Rohrich RJ. Clearing the smoke: the scientific rationale for tobacco abstention with plastic surgery. Plast Reconstr Surg. 2001;15;108(4):1063-73.

Landau AG, Hudson DA, Adams K, Geldenhuys S, Pienaar C. Full-thickness skin grafts: maximizing graft take using negative pressure dressings to prepare the graft bed. Ann Plast Surg. 2008; 60(6): 661-666.

Lineaweaver WC, Lei MP, Mustain W, Oswald TM, Cui D, Zhang F. Vascular endothelium growth factor, surgical delay, and skin flap survival. Ann Plast Surg. 2004; 239(6): 866-875.

Lofêgo Filho JÁ, Dadalti P, Souza DC, Souza PRC, Silva MAL, Takiya CM. Enxertia de pele em oncologia cutânea. An. Bras. Dermatol. 2006; 81(5).

Ma L, Wang WP, Chow JYC, Yuen ST, Cho CH. Reduction of EGF is associated with the delay of ulcer healing by cigarette smoking. Am J Physiol Gastrointest Liver Physiol. 2000; 278(1):10-17.

Maderal AD, Kirsner RS. Clinical and Economic Benefits of Autologous Epidermal Grafting.Cureu. 2016; 8(11).

Maeda M, Nakamura T, Fukui A, Koizumi M, Yamauchi T et al. The role of serum imbibition for skin grafts. Plast Reconstr Surg. 1999;104(7):2100-7. 
Mazurkiewicz-Pisarek A, Płucienniczak G, Ciach T, Płucienniczak A. The factor VIII protein and its function. Acta Biochim Pol. 2015;63 (1):11-16.

McGinnis, M.E.; Vanable, J.W., Jr. Voltage gradients in newt limb stumps. Prog. Clin. Biol. Res. 1986, 210, 213-238.

Medeiros AC, Lima FP, Dantas Filho AM, Melo NMC, Azevedo I.M. A nicotina atua como fator deletério na reparação da parede abdominal. Acta Cir Bras. 2003; 18.

Michaud SE, Ménard C, Guy LG, Gennaro G, Rivard A. Inhibition of hypoxia-induced angiogenesis by cigarette smoke exposure: impairment of the HIF-1alpha/VEGF pathway. FASEB J. 2003; 17(9):1150-2.

Midttun M, Sejrsen P, Paaske WP. Smokers have severely disturbed peripheral microcirculation. Int Angiol. 2006; 25(3):293-6.

Mehmandoust FG, Torkaman G, Firoozabadi M, Talebi G.Anodal and cathodal pulsed electrical stimulation on skin wound healing in guinea pigs. J Rehabil Res Dev. 2007; 44(4):611-8.

Mengel M, Gwinner W,Schwarz A,Bajeski R,Franz I, Bröcker V, Becker T, Neipp M, Klempnauer J, Haller $\mathrm{H}$, Kreipe $\mathrm{H}$. Infiltrates in protocol biopsies from renal allografts, Am J Transplant. 2007;7 (2): 356-65.

Mengel M, Reeve J, Bunnag S, Einecke G, Sis B, Mueller T, Kaplan B, Halloran PF. Molecular correlates of scarring in kidney transplants: the emergence of mast cell transcripts. Am J Transplant. 2009;9 (1):169-78.

Mohajeri-Tehrani MR, Nasiripoor F, Torkaman G, Hedayati M, Annabestani Z, Asadi MR. Effect of low intensity direct current on expression. Of vascular endothelial growth factor and nitric oxide in diabetic foot ulcers. Journal of Rehabilitation Research and Development. 2014;51 (5), 815-24.

Nease C. Using low pressure, negative pressure wound therapy for wound preparation and management of split-tickeness skin grafts in three patients with complex wounds. Ostomy Wound Manag. 2009; 55(6): 32-42.

Neves, L. M. S, Marcolino, A. M., Prado, R. P, Thomazini, J. A. Laser 830nm na viabilidade do retalho cutâneo de ratos submetidos a nicotina. Acta Ortopédica Brasileira. 2011;19: 342-345. 
Neves LM, Guirro EC, Albuquerque FL,Marcolino AM. Effects of High-Voltage Electrical Stimulation in Improving the Viability of Musculocutaneous Flaps in Rats. Ann Plast Surg. 2016; 77(4):50-4.

Nelson RM, Hayes KW, Currier DP. Eletroterapia Clínica. $3^{\text {a }}$ ed. Barueri: Manole; 2003.

Nishimura KY, Isseroff RR, and Nuccitelli R: Human keratinocytes migrate to the negative pole in direct current electric fields comparable to those measured in mammalian wounds. J Cell Sci 1996; 109.

Nuccitelli R, Erickson CA. Embryonic cell motility can be guided by physiological electric fields. Exp Cell Res. 1983; 147:195-201.

Nuccitelli R. A role for endogenous electric fields in wound healing. Curr Top Dev Biol. 2003; 58:1-26.

Ojingwa JC, Isseroff RR. Electrical stimulation of wound healing. J Invest Dermatol. 2003; 121(1):1-12.

Orida N, Feldman JD. Directional protrusive pseudopodial activity and motility in macrophages induced by extracellular electric fields. Cell Motil. 1982; 2(3):243-55.

Pluvy I, Garrido I, Pauchot J, Saboye J, Chavoin JP, Tropet Y, Grolleau JL, Chaput B.Smoking and plastic surgery, part I. Pathophysiological aspects: update and proposed recommendations. Ann Chir Plast Esthet. 2015; 60(1): 3-13.

Polak A, Franek A, Taradaj J.High-Voltage Pulsed Current Electrical Stimulation in Wound Treatment.Adv Wound Care. 2014; 3(2):104-117.

Prindeze NJ, Hoffman HA, ArdanuyJG, Zhang J, Carney BC, Moffatt LT, Shupp JW. Active Dynamic Thermography is a Sensitive Method for Distinguishing Burn Wound Conversion. J Burn Care Res. 2016; 37(6): 559-568.

Sebastian A, Syed F, Perry D, Balamurugan V, Colthurst J, Chaudhry IH, et al. Acceleration of cutaneous healing by electrical stimulation: Degenerate electrical waveform down-regulates inflammation, up-regulates angiogenesis and advances remodeling in temporal punch biopsies in a human volunteer study. Wound Repair Regen. 2011; (19) 693-708. 
Seyhan T. Split-thickness skin graft. Skin Grafts - Indications, Applications and Current Research: InTech. 2011.

Selçuk CT, Kuvat SV, Bozkurt M, Yaşar Z, Gülsün N, Ilgezdi S, Ula M, Ozalp B. The effect of hyperbaric oxygen therapy on the survival of random pattern skin flaps in nicotine-treated rats. J Plast Reconstr Aesthet Surg. 2012; 65(4):489-93.

Shah A, Pfaff MJ, Assi R, Wu W, Steinbacher DM. PDE-5 inhibition improves skin flap viability in rats that are exsilveiraposed to nicotine. Microsurgery. 2014; 34(5):3907.

Sheehan P, Jones P, Caselli A, Giurini JM, and Veves A: Percent change in wound area of diabetic foot ulcers over a 4-week period is a robust predictor of complete healing in a 12-week prospective trial. Diabetes Care 2003; 26: 1879.

Siana JE, Rex S, Gottrup F. The effect of cigarette smoking on wound healing. Scand J Plast Reconstr Surg Hand Surg. 1989; 23: 207-209.

Silva EFH, Martins CC, Guirro ECO, Guirro RRJ. Estimulação elétrica de alta voltagem como alternativa para o tratamento de úlceras crônicas de membros inferiores. An Bras Dermatol. 2010; 85(4): 567-569.

Silveira CA. Estudo da regeneração óssea guiada em mandíbula de ratos idosos. Dissertação (Mestrado em Ciências) - Faculdade de Medicina, Universidade de São Paulo. 2012

Soong HK, Parkinson WC, Bafna S, et al. Movements of cultured corneal epithelial cells and stromal fibroblasts in electric fields. Invest Ophthalmol Vis Sci. 1990;31:2278-2282.

Skinovsky, J. A. A influência da nicotina na cicatrização de anastmoses do intestine delgado em ratos. Curitiba, 2000. Dissertação (Mestrado em Clínica Cirúrgica) - Setor de Ciências da Saúde, Universidade Federal do Paraná.

Silverstein P. Smoking and wound healing. Am J Med. 1992; 93(1A): 22-24.

Sørensen LT, Jørgensen S, Petersen LJ, Hemmingsen U, Bülow J, Loft S, Gottrup F. Acute effects of nicotine and smoking on blood flow, tissue oxygen, and aerobe metabolism of the skin andsubcutis. J Surg Res. 2009; 152 (2): 224-230. 
Sørensen LT, Toft BG, Rygaard J, Ladelund S, Paddon M, James T, Taylor R, Gottrup F. Effect of smoking, smoking cessation, and nicotine patch on wound dimension, vitamin C, and systemic markers of collagen metabolism.Surgery. 2010; 148(5):982-90.

Stephenson AJ, Griffiths WR, La Hausse-Brown TP. Patterns of contraction in human full thickness skin grafts. Br J Plast Surg. 2000; 53:397-402.

Su Y, Cao W, Han Z, Block ER. Cigarette smoke extract inhibits angiogenesis of pulmonary artery endothelial cells: the role of calpain. Am J Physiol Lung Cell Mol Physiol. 2004; 287(4):794-800.

Talebi G, Torkaman G, Firoozabadi M, Shariat S. Effect of anodal and cathodal microamperage direct current on the skin wound healing: a biomechanical and histological study. J Biomech. 2007; 40:662.

Talebi G, Torkaman G, Firoozabadi M and Shariat S: Effect of anodal and cathodic microamperation continuous current electric stimulation on lesion potential and wound size in guinea pigs. J Rehabil Res Dev 2008; 45: 153.

Thakral G, Lafontaine J, Najafi B, Talal TK, Kim P, Lavery LA. Electrical stimulation to accelerate wound healing. Diabet Foot Ankle. 2013; 16:4.

Ud-Din S, Bayat A.Electrical Stimulation and Cutaneous Wound Healing: A Review of Clinical Evidence. Healthcare. 2014; 2(4):445-67.

Ud-Din S, Sebastian A, Giddings P, Colthurst J, Whiteside S, Morris J, Nuccitelli R, Pullar C, Baguneid M, Bayat A. Angiogenesis is induced and wound size is reduced by electrical stimulation in an acute wound healing model in human skin. PLoS One. $2015 ; 30: 10(4)$.

Vodovnik L, Karba R. Treatment of chronic wounds by means of electric and electromagnetic fields. Part 1. Literature review. Med Biol Eng Comput. 1992;30(3):257-66.

Young T, Fowler A. Tratamento de feridas: gerenciamento de enfermagem nos locais doadores e receptores de enxertos de pele. Wound healing: nursing procedures. Nursing 1998; 1(3): 18-25.

Wahie, S, CM Lawrence, CM. Wound complications following diagnostic skin biopsies in dermatology inpatients. Arch Dermatol. 2007;143 (10):1267-71. 
Weiss DS, Kirsner R, Eaglstein WH.Electrical stimulation and wound healing. Arch Dermatol. 1990;126 (2):222-5.

Witte MB \& Barbul A. General principles of wound healing. Surg Clin North Am. 1997; 77(3):509-28.

Xanthoulea S, Deliaert A, Romano A, Rensen SS, Buurman WA, van der Hulst RR. Nicotine effect on inflammatory and growth factor responses in murine cutaneous wound healing. Int Immunopharmacol. 2013; 17(4): 1155-1164.

Zhang F, Fischer K, Komorowska-Timek E, Guo M, Cui D, Dorsett-Martin W, Buncke HJ, Lineaweaver WC. Improvement of skin paddle survival by application of vascular endothelial growth factor in a rat tram flap model. Ann Plast Surg. 2001; 46: 314-19.

Zhao M; Bai H; Wang E; Forrester JV, McCaig CD. Electrical stimulation directly induces pre-angiogenic responses in vascular endothelial cells by signaling through VEGF receptors. J Cell Sci. 2004; 117(3): 397-405

Zhao M, Penninger J, Isseroff RR. Electrical activation of wound-healing pathways. Adv Skin Wound Care. 2010.

Zia S, Ndoye A, Lee TX, Webber RJ, Grando SA. Receptor-mediated inhibition of keratinocyte migration by nicotine involves modulations of calcium influx and intracellular concentration. J Pharmacol Exp Ther. 2000; 293(3): 973-81.

Zografou A, Papadopoulos O, Tsigris C, Kavantzas N, Michalopoulos E, Chatzistamatiou $\mathrm{T}$, et al. Autologous transplantation of adipose-derived stem cells enhances skin graft survival and wound healing in diabetic rats. Ann Plast Surg. 2013; 71: 225-32. 
Anexo 


\section{ANEXO A - Comitê de ética em Pesquisa}

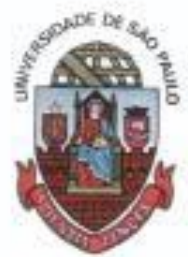

UNIVERSIDADE DE SÃO PAULO

FACULDADE DE MEDICINA DE RIBEIRÃO PRETO

COMISSÄO DE ÉTICA NO USO DE ANIMAIS

\section{CER TIFICADO}

Certificamos que o Protocolo para Uso de Animais em Experimentação $\mathrm{n}^{\circ} 147 / 2015$, sobre o projeto intitulado "Efeito da estimulação elétrica de alta voltagem na integração de enxertos de pele total em ratos submetidos à ação da nicotina", sob a responsabilidade da Professora Doutora Elaine Caldeira de Oliveira Guirro está de acordo com os Princípios Éticos em Experimentação Animal adotado pelo Conselho Nacional de Controle de Experimentação Animal (CONCEA) e foi APROVADO em reunião de 27 de janeiro de 2016.

We certify that the protocol $n^{\circ} 147 / 2015$, entitled "Effect of high volt electrical stimulation in total skin graft integration in rats submitted to action of nicotine", is in accordance with the Ethical Principles in Animal Research adopted by the National Council for the Control of Animal Experimentation (CONCEA) and was approved by the Local Animal Ethical Committee from the Ribeiråo Preto Medical School of the University of São Paulo in $01 / 27 / 2016$.

Ribeirão Preto, 27 de janeiro de 2016.

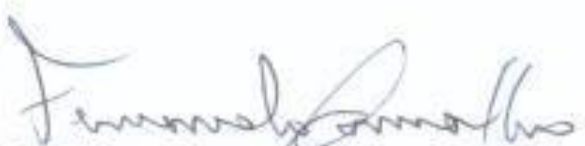

Prof. Dr. Fernando Silva Ramalho

Presidente da CEUA - FMRP - USP

Comissão de Ética no Uso de Animais da Faculdade de Medicina de Ribeiräo Preto da Universidade de S3̆o Paulo - (16) 3315-3301 